Article

\title{
Energy-Based Prediction of the Displacement of DCFP Bearings
}

\author{
Jiaxi Li ${ }^{1, *}$, Shoichi Kishiki ${ }^{2}$, Satoshi Yamada ${ }^{3, *}$, Shinsuke Yamazaki ${ }^{4}$, Atsushi Watanabe ${ }^{4}$ \\ and Masao Terashima ${ }^{4}$ \\ 1 Department of Architecture and Building Engineering, School of Environment and Society, \\ Tokyo Institute of Technology, J2-21, 4259 Nagatsuta, Midori-ku, Yokohama 226-8503, Japan \\ 2 Laboratory for Future Interdisciplinary Research of Science and Technology, Institute of Innovative Research, \\ Tokyo Institute of Technology, J2-21, 4259 Nagatsuta, Midori-ku, Yokohama 226-8503, Japan; \\ kishiki.s.aa@m.titech.ac.jp \\ 3 Department of Architecture, Graduate School of Engineering, The University of Tokyo, 7-3-1, Hongo, \\ Bunkyo-ku, Tokyo 113-8656, Japan \\ 4 Nippon Steel Engineering, Osaki Center Building, 1-5-1 Osaki, Shinagawa, Tokyo 141-8604, Japan; \\ yamazaki.shinsuke.f5g@eng.nipponsteel.com (S.Y.); watanabe.atsushi.8hx@eng.nipponsteel.com (A.W.); \\ terashima.masao.mx4@eng.nipponsteel.com (M.T.) \\ * Correspondence: li.j.ax@m.titech.ac.jp (J.L.); s_yamada@arch1.t.u-tokyo.ac.jp (S.Y.)
}

Received: 26 June 2020; Accepted: 28 July 2020; Published: 30 July 2020

\begin{abstract}
Isolation systems are currently being widely applied for earthquake resistance. During the design stage for such systems, the displacement response and input energy of the isolation layer are two of the main concerns. The prediction of these values is also of vital importance during the early stages of the structural design. In this study, the simple prediction method of double concave friction pendulum (DCFP) bearings is proposed, which can relate the response displacement of the isolation layer to the ground velocity through energy transfer with sufficient accuracy. Two friction models (the precise and simplified model) and a constant friction coefficient of double concave friction pendulum (DCFP) bearings are comprehensively validated by full-scale sinusoidal dynamic tests under various conditions. In addition, a response analysis, based on previous studies, was conducted using the friction models under selected unidirectional earthquake excitations, and the accuracy of using the simplified model in the response analysis was verified. Based on the response analysis data, this article verifies and optimizes the proposed prediction method by parameterizing the characteristics of earthquakes and combining the energy balance in order to gain a deeper understanding of the design of the isolation systems.
\end{abstract}

Keywords: seismic isolation; double concave friction pendulum bearing; full-scale dynamic test; friction dependencies; prediction method; response displacement; input energy; isolation system design

\section{Introduction}

Many kinds of isolators are currently being proposed, and the isolation system is being widely applied for earthquake resistance [1-5]. A double concave friction pendulum (DCFP) bearing, which is a type of base isolation technique that detaches structures from the ground to help stabilize buildings during earthquakes, is widely used in earthquake-prone regions. Its composition is shown in Figure 1. 


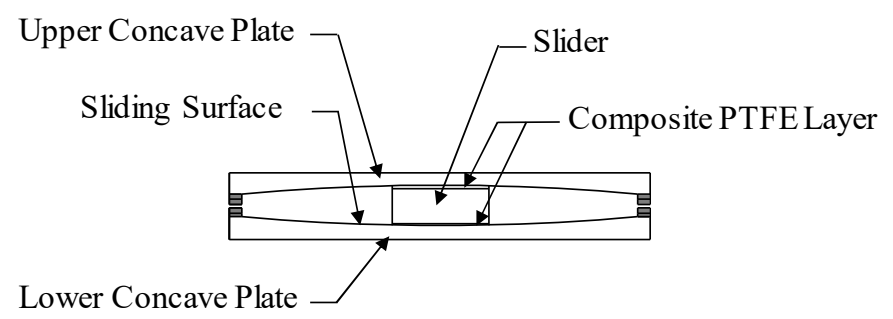

Figure 1. Composition of a double concave friction pendulum (DCFP) bearing.

The clear force-displacement relationship of friction pendulum bearings (FPBs) makes numerical analysis one of the best ways in which to study and predict their performance. The main focus is on the calculation of the friction force. This is because the friction coefficient's dependence on pressure, velocity and temperature is the most important characteristic for the performance of a FPB (Friction Pendulum Bearing). Therefore, the lubricant material used in an FPB and the characteristics of this material are very important. Quaglini et al. (2012) proposed an experimental methodology for the characterization of self-lubricating materials based on pressure, velocity, external temperature and displacement through small-scale specimens [1]. In addition to external temperature, particular attention was paid to the temperature increase on the sliding surface caused by friction heating because this increase in temperature had a significant influence on the behavior of the FPB during an earthquake event. Moreover, the measurement of this temperature increase is very difficult to perform during dynamic excitation. To confront this difficulty, Lomiento et al. (2013) proposed a friction model that takes into account the vertical load, velocity and cycling effect (degradation of friction characteristics due to the repetition of cycles and consequent temperature rise) by performing 1D prototype dynamic tests on single concave friction pendulum (SCFP) bearings [2]. Quaglini et al. (2014) proposed a 3D finite element model (FEM) of an SCFP bearing to estimate friction heating, and the estimated temperature was validated with experimental data measured by thermocouples embedded in the concave sliding plate [3]. Following this work, some studies proposed simplified temperature simulation methods. Kumar et al. (2015) proposed a simplified model to calculate the representative temperature of the sliding surface in thermal calculations (Method 2 in the article) and considered pressure, velocity and temperature dependency. The analysis results were verified by 2D prototype dynamic tests of the SCFP bearings [4]. The distributions of the maximum displacement under 30 sets of ground motions in the original model (Method 1 in the article) and the simplified model were compared, and a relatively small difference was found between the models; thus, the simplified model could be applied instead of the original model. Furthermore, with the appearance of multiple concave friction pendulum bearings (MCFP bearings), Bianco et al. (2018) proposed a simplified rheological model to simulate the temperature rise in the MCFP bearings [5].

\section{State-of-the-Art Isolator Displacement Prediction}

Two of the main matters of concern during the design of the isolation systems were (I) whether the maximum displacement response of the isolation layer during the earthquake was within the capacity and (II) in the aspect of energy, whether the energy absorption capacity of the isolation system was enough in comparison to the input energy during the earthquake. In the design, nonlinear time-history analysis could be conveniently performed to obtain these values. However, in the early stages of the structural design, the structural configurations were not well defined. Thus, simplified prediction methods were generally introduced in various structural codes to obtain the design displacement or the energy demand of the isolation system under the specified seismic loads:

(I) Typical Simplified Prediction Methods for the Design Displacement of the Isolation System Introduced in ASCE (American Society of Civil Engineers), Euro Code and AIJ (Architectural Institute of Japan) [6-8]. 
The methods introduced in ASCE and Euro Code are similar: they can predict the response displacement and the response force based on the simplified method of equivalent linear analysis under certain conditions. However, the two methods introduced in AIJ can give the tendency of the response reduction or the relation between the response force and displacement under various parameters by using the equivalent SDOF (Single Degree of Freedom) system or using energy balance, respectively.

\section{(1) Equivalent Lateral Force Procedure (ASCE [6])}

This method can be applied for the design of a seismically isolated structure if it meets several requirements, including the structure being located at a site with $S_{1}$ (mapped acceleration parameter at one-second periods) less than $0.60 \mathrm{~g}$; the effective period of the isolated structure at the maximum displacement, $T_{M}$, being less than or equal to $3.0 \mathrm{~s}$; and so on. Based on this method, the design displacement, $D_{D}$, can be predicted.

$$
D_{D}=\frac{g \times S_{D 1} \times T_{D}}{4 \times \pi^{2} \times B_{D}}
$$

where $S_{D 1}$ is the spectral acceleration parameter at $1 \mathrm{~s}$ periods, $T_{D}$ is the effective period of the seismically isolated structure, $B_{D}$ is the numerical coefficient related to the effective damping and $g$ is the gravity acceleration.

\section{(2) Simplified Linear Analysis (Euro Code [7])}

Similar to the equivalent lateral force procedure introduced in ASCE, this method may be applied to isolation systems with equivalent linear damped behavior if they also conform to conditions such as the distance from the site to the nearest potentially active fault, with a magnitude $M \geq 6.5$, being greater than $15 \mathrm{~km}$ and their effective period being smaller than $3 \mathrm{~s}$ and larger than three times the fundamental period of the superstructure, assuming a fixed base. It assumes that the superstructure is a rigid solid, and then the displacement of the stiffness center, due to the seismic action, can be calculated in each horizontal direction, from the following expression:

$$
d_{d c}=\frac{M \times S_{c}\left(T_{e f f}, \xi_{e f f}\right)}{K_{e f f, \min }}
$$

where $S_{c}\left(T_{\text {eff }}, \xi_{\text {eff }}\right)$ is the spectral acceleration defined by an elastic response spectrum that takes into account the appropriate value of the effective damping $\xi_{\text {eff. }}$. $K_{\text {eff }}$ is the effective horizontal stiffness of the isolation system, and $T_{\text {eff }}$ is the effective period.

(3) Simplified Response Prediction Method for the Maximum Response Using an Equivalent Single-Degree-of-Freedom System (AIJ [8]

The simple prediction for the maximum response values of an equivalent SDOF system involves the evaluation of the dynamic characteristics of the structure by using viscous damping and hysteretic damping, followed by the prediction of the maximum response using an elastic response spectrum.

Two variations are included. In the response prediction method 1, the maximum response is obtained through a convergence calculation that considers the changes in the equivalent period and in the equivalent damping factor due to the yielding of the SDOF system in the spectrum response. For the response prediction method 2, Method 1 is simplified based on the assumption that the response spectrum curve is constant, regardless of the period. The maximum response is also estimated by some response curves. By using these curves, it is possible to grasp visually the tendency of the response reduction in the structures without a convergence calculation.

(4) Response Prediction of the Seismic Isolation Level Based on Energy Balance (AIJ [8]) 
The energy balance method is an analysis method that evaluates seismic resistance based on the balance of the seismic input energy to buildings due to ground motions via energy spectra and the energy absorbed by the building.

In this method, the relationship between the maximum shear force coefficient and the maximum displacement (response reduction effect) of the seismic isolation level can be shown in the curves that are related to the seismic isolation period and ground motion level, by assuming that the total hysteresis energy absorbed during the earthquake is equal to the energy dissipated by two repetitions of the steady state loop at the maximum displacement.

In the above methods, (1) and (2) are based on equivalent linear analysis with strict application conditions. Meanwhile, (3) and (4) provide the tendency of the response reduction, but the response displacement of the isolation layer cannot be predicted under the specified seismic loads.

(II) Simplified Prediction Methods for the Energy Demand of the Isolation System Introduced in Some Design Methods Based on the Energy Concept [9-12].

Besides the maximum response of the structure, the input energy is also very important for earthquake design methods based on the energy concept [9], in which the energy demand can be taken as the input energy. This value is usually given as the energy spectrum, which can provide the input energy to structures during an earthquake [10]. However, this process is based on response analysis under a certain earthquake record, which makes it difficult to relate the input energy to the characteristics of the group of earthquakes in the construction site. Thus, some methods that can predict the total input energy based on earthquake characteristics were proposed in some earthquake design methods based on energy [11]:

\section{(1) Approximate Inelastic Input Energy Spectra}

Based on Iwan's study [10], it was found that an inelastic input energy spectrum could be approximated by an elastic spectrum that corresponds to an equivalent viscous damping and an equivalent natural period. However, Hadjian [12] has shown that this method is not suitable for ground motions with a highly harmonic nature.

\section{(2) Another Method Proposed by Uang [11]}

This method can predict the maximum input energy of a structure with a specified ductility ratio if the strong motion duration at a given site is known. However, this maximum value is the maximum input energy that is evaluated throughout the whole period range and means that the maximum input energy of a structure within a specific period cannot be predicted.

The energy balance equation used in this study is shown in Equation (3) [11]. When an isolation system consisting of DCFP bearings is subjected to earthquake ground motions, the input energy $E$ is accumulated in the elastic strain energy of the bearing, $E_{s}$, and the kinetic energy of the upper structure, $E_{k}$, and is mainly consumed by the frictional resistance of the bearing in $E_{h}$ and by the damping of the system in $E_{\xi}$ :

$$
E=E_{s}+E_{k}+E_{h}+E_{\xi}
$$

where,

$$
\begin{gathered}
E=-\int m \times a g \times d y \\
E_{k}=\frac{m \times v^{2}}{2}
\end{gathered}
$$

In these formulas, $E$ is the total input energy (the relative input energy in [11]), $E_{S}$ is the elastic strain energy, $E_{k}$ is the kinetic energy (the relative kinetic energy in [11]), $E_{h}$ is the hysteresis energy, $E_{\xi}$ is the damping energy, $\mathrm{m}$ is the mass of the upper structure, $a g$ is the ground acceleration, $d y$ is the a 
segment of the relative displacement between the upper structure and the ground and $\mathrm{v}$ is the relative velocity between the upper structure and the ground.

Akiyama has shown that the total input energy, E, based on the SDOF system, can provide a very good estimate of the input energy for multi-story buildings [9]. Therefore, in this study, an SDOF system with a damping ratio of $0 \%$ was applied in order to simplify the computation and to make the influence of the earthquake inputs on the response of the DCFP bearings clearer. As a result, the input energy can be expressed as:

$$
E=E_{s}+E_{k}+E_{h}
$$

To sum up, in the early stages of the structural design, simple response prediction methods are of vital importance. Two categories of prediction methods are usually applied, as introduced above: methods based on equivalent linear analysis and methods based on energy demand and supply. The first category mainly focuses on the response displacement of the isolation layer, and the second category mainly concerns the input energy of the isolation system. Furthermore, most methods in both categories function according to the response spectrum or the energy spectrum from the response analysis. However, this study proposed a method that is directly based on the characteristics of earthquake records and can relate both the response displacement and the input energy to the ground velocity history with sufficient accuracy. Therefore, a deeper understanding can be gained in order to provide another perspective for the design methods for isolation systems.

\section{Performed Experiments}

\subsection{Testing Setup}

The experiments in this study were conducted at the University of California, San Diego, in the Caltrans Seismic Response Modification Device (SRMD) Test Facility [13]. An overview of the test setup is shown in Figure 2. After the specimen was placed inside the facility, an axial force was added to control the contact pressure between the slider and the concave plate. Additionally, four horizontal actuators made the loading table move horizontally in order to control the velocity and loading path.

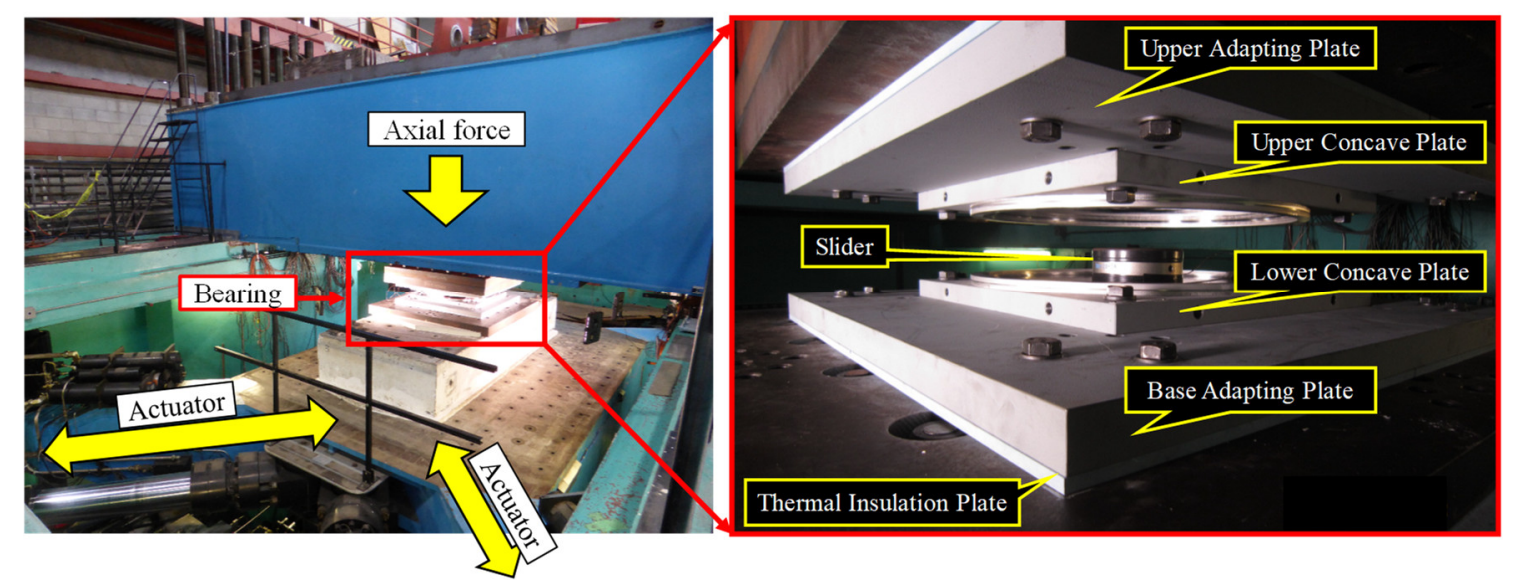

Figure 2. Test setup.

\subsection{Dependency Tests}

Pressure, velocity and temperature dependency equations were introduced in previous studies [14-16]. The applicability of the pressure and velocity dependency equations for specimens with slider diameters of 300 and $400 \mathrm{~mm}$ and spherical radii of the concave plates $\left(R_{S}\right)$ of $4500 \mathrm{~mm}$ were verified under different pressures through the dependency test introduced in Table 1 . The input waves were unidirectional sinusoidal displacement variations, and the amplitude, maximum velocity (Vmax), period and number of cycles were determined. 
Table 1. Test procedure of the dependency test.

\begin{tabular}{|c|c|c|c|c|c|c|}
\hline Spec. & Test & Pressure & Amplitude & Vmax & Period & Cycle \\
\hline num. & num. & $\mathrm{N} / \mathrm{mm}^{2}$ & $\pm \mathbf{m m}$ & $\mathrm{mm} / \mathrm{s}$ & $\mathbf{s}$ & num. \\
\hline \multirow{6}{*}{$\varphi 300 \varphi 400$} & \multicolumn{6}{|c|}{ (1) Velocity dependency test } \\
\hline & T01 & 60 & 200 & 400 & 3.14 & 4 \\
\hline & \multicolumn{6}{|c|}{ (2) Pressure dependency test } \\
\hline & T02 & 40 & & 20 & 62.83 & 4 \\
\hline & T03 & 60 & 200 & 20 & 62.83 & 4 \\
\hline & T04 & 80 & & 20 & 62.83 & 4 \\
\hline
\end{tabular}

\subsection{ASCE Tests}

The dynamic tests shown in Table 2 were conducted to validate the friction models under various situations. The test procedure was designed based on ASCE/SEI 7-16. Thus, it was named the ASCE test.

Table 2. Test procedure of the ASCE test.

\begin{tabular}{ccccccc}
\hline Spec. & Test & Pressure & Amplitude & Vmax & Period & Cycle \\
\hline num. & num. & $\mathbf{N} \backslash \mathbf{m m}^{\mathbf{2}}$ & $\mathbf{\pm m m}$ & $\mathbf{m m} / \mathbf{s}$ & $\mathbf{s}$ & $\mathbf{n u m .}$ \\
\hline & T01 & & 268 & 392 & 4.26 & 3 \\
& T02 & & 10 & 14.646 & 4.26 & 20 \\
& T03 & & 100 & 146.369 & 4.26 & 3 \\
& T04 & 60 & 200 & 292.738 & 4.26 & 3 \\
& T05 & & 268 & 392.269 & 4.26 & 3 \\
& T06 & & 400 & 585.476 & 4.26 & 3 \\
& T07 & & 400 & 585.476 & 4.26 & 3 \\
& T08 & 40 & 400 & 585.476 & 4.26 & 3 \\
& T09 & 80 & 400 & 585.476 & 4.26 & 3 \\
& T10 & 30 & 440 & 644.024 & 4.26 & 1 \\
& T11 & 90 & 440 & 644.024 & 4.26 & 1 \\
& T12a & & & & & 7 \\
& T12b & & 300 & 439.107 & 4.26 & 7 \\
& T12c & 60 & & & & 6 \\
& T13 & & 268 & 392.269 & 4.26 & 3 \\
\hline
\end{tabular}

\section{Numerical Simulation of the Experiments}

\subsection{Friction Dependency}

The pressure dependency of the friction coefficient could be considered by a pressure dependency factor $\gamma$, which is related to the bearing stress $\sigma$ at the contact area of the concave plate and the slider. The pressure dependency equation was obtained by a previous experimental study [14]:

$$
\gamma=2.03 \times \sigma^{-0.19}+0.068
$$

The dependency of the friction coefficient on velocity was considered by a velocity dependency factor $\alpha$. This factor was related to the velocity of the upper concave plate relative to the lower concave plate $v$, which could be described by the following equation [14]:

$$
\alpha=1-0.55 \times e^{-0.019 v}
$$

Figure 3 shows the applicability verification of the pressure and velocity dependency equations for $\varphi 300$ and $\varphi 400$ specimens, based on the dependency test introduced in Table 1. In Figure 3, the experimental friction coefficients calculated from the dependency test were normalized by the 
values at $60 \mathrm{~N} / \mathrm{mm}^{2}$ and $400 \mathrm{~mm} / \mathrm{s}$, respectively, in order to minimize the influence of product variation. As a result, Equations (7) and (8) are both highly consistent with the experimental results, and thus, the previously proposed pressure and velocity dependency equations are effective for DCFP bearings with $\varphi 300$ and $\varphi 400$ slider diameters.

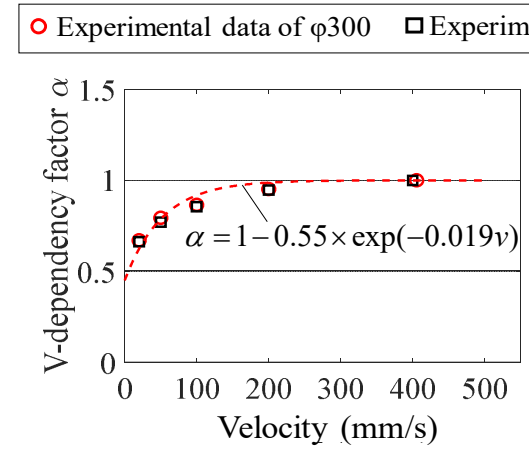

(a)

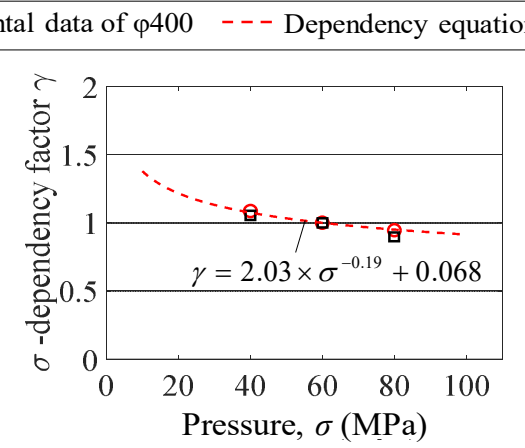

(b)

Figure 3. Verification of (a) pressure and (b) velocity dependency equations through the dependency test.

The temperature dependency equation is as follows:

$$
\beta=1.13 \times \exp (-0.007 T)
$$

where $\beta$ is the temperature dependency factor and $T$ is the temperature of the contact area between the slider and the concave plate in Celsius $[15,16]$. As the temperature, $T$, is difficult to accurately measure during testing, a numerical method proposed by Constantinou, M.C. et al. [4,17] will be introduced to simulate the temperature in the next section.

The friction coefficient at each time during excitation can be calculated by:

$$
\mu=\mu_{0} \times \gamma \times \alpha \times \beta
$$

where $\mu, \gamma, \alpha$ and $\beta$ are the friction coefficient, pressure dependency factor, velocity dependency factor and temperature dependency factor at each time, respectively, and $\mu_{0}$ is the friction coefficient at $60 \mathrm{~N} / \mathrm{mm}^{2}(\gamma=1), 400 \mathrm{~mm} / \mathrm{s}(\alpha=1)$ and an atmosphere temperature of around $20^{\circ} \mathrm{C}(\beta=1)$, which was selected as 0.075 for all the specimens in this study. $\mu_{0}$ was calculated from the trend line of the friction coefficient versus the time from the dependency test T01 in Table 1, which was when the time was approaching zero, as shown in Figure 4. The experimental values in this figure represent the friction coefficients near zero displacement where the velocity was $400 \mathrm{~mm} / \mathrm{s}$ and the pressure was $60 \mathrm{~N} / \mathrm{mm}^{2}$.

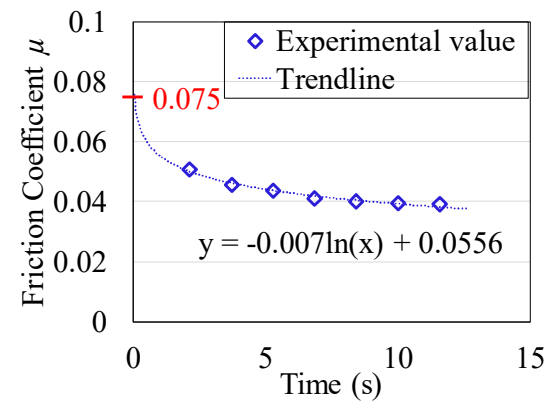

Figure 4. Determination of $\mu_{o}$.

\subsection{Friction Models}

Two friction models are proposed as precise and simplified models, and both considered the pressure, velocity and temperature dependency introduced in Section 4.1. Meanwhile, the precise 
model applies the precise temperature simulation model shown in Figure 5a and the simplified model applies the simplified temperature simulation model shown in Figure $5 b$, where $r_{\text {contact }}$ is the radius of the bearing and the monitor points are virtual points in the model used for temperature simulation, which is proposed by Constantinou, M.C. et al. [4,17]. As the precise model has a lot of monitoring points along the sliding direction, the simulation results are more precise. However, for the simplified model, which only applies one monitoring point, the calculation speed is much faster. Therefore, the validation of the simplified model is very important in judging whether it can be used instead of the precise model.

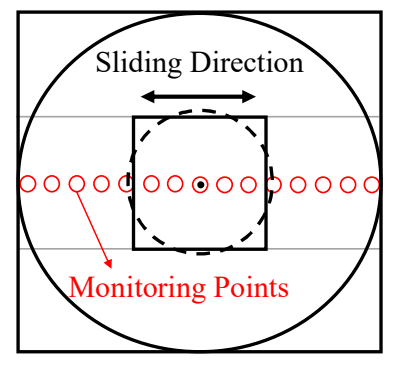

(a)

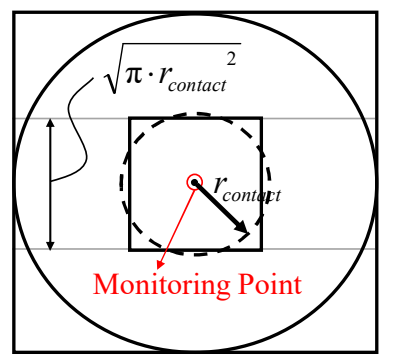

(b)

Figure 5. Temperature simulation models used in the (a) precise model and (b) simplified model.

In both the precise model and the simplified model, the temperature increase of the monitoring points can be calculated by [17]:

$$
\Delta T(t)=\frac{\sqrt{D}}{k \sqrt{\pi}} \int_{0}^{t} \frac{q(t-\tau) d \tau}{\sqrt{\tau}}
$$

where $q(t)$ is the heat flux at the surface of the solid; $\Delta T(t)$ is the temperature increase at time $t$, compared to the temperature at $t=0 ; \tau$ is a time parameter that varies between 0 and $t ; D$ is the thermal diffusivity of the solid; and $k$ is the thermal conductivity of the solid [17]. In this study, the values of $k$ and $D$ were adopted from the "JSME Data Book: Heat Transfer", which are $0.016 \mathrm{~W} /\left(\mathrm{mm} \cdot{ }^{\circ} \mathrm{C}\right)$ and $4.07 \mathrm{~mm}^{2} / \mathrm{s}$, respectively [18]. Then the temperature at the contact surface of the slider and the concave plates can be calculated by taking average of the temperature of the monitoring points within the contact surface.

For DCFP Bearings, the instantaneous heat flux, $q(t)$, can be defined as follows [4]:

$$
q(t)=\left\{\begin{array}{cc}
\mu(t) p(t) \frac{v(t)}{2} \text { if } \delta \leq & \sqrt{\pi \cdot r_{\text {contact }^{2}}} / 2 \\
0 & \text { otherwise }
\end{array}\right.
$$

where $\mu(t), p(t)$ and $v(t)$ are the coefficient of friction, the pressure at the contact area and the relative velocity between the upper and lower concave plates at time $t$, respectively; $\delta$ is the lateral distance from the center of the slider to the monitor point of interest and $r_{\text {contact }}$ is the contact radius.

\subsection{Numerical Results Using Friction Models}

The comparison of the first hysteresis curve between the friction models and the experimental results of the DCFP bearings with $400 \mathrm{~mm}$-diameter sliders under both strong and weak excitations are shown in Figure 6, and show high accuracy for both friction models. The input excitations in Figure $6 \mathrm{a}, \mathrm{b}$ are the first cycles in T01 and T02 of the ASCE test, respectively. Meanwhile, as an error criterion, the values of the post-yield stiffness, effective stiffness, effective damping and energy dissipated per cycle were also calculated to quantify the validity of the models [6]. In all of the ASCE tests, the simplified model shows a similar accuracy to the precise model, with both models showing high accuracy in the simulation of the behaviours of the DCFP bearings [19]. 


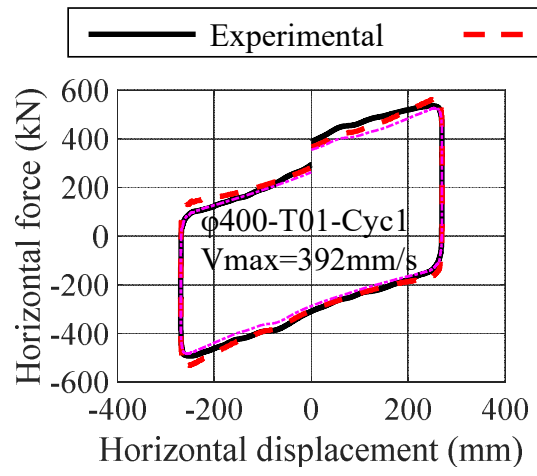

(a)

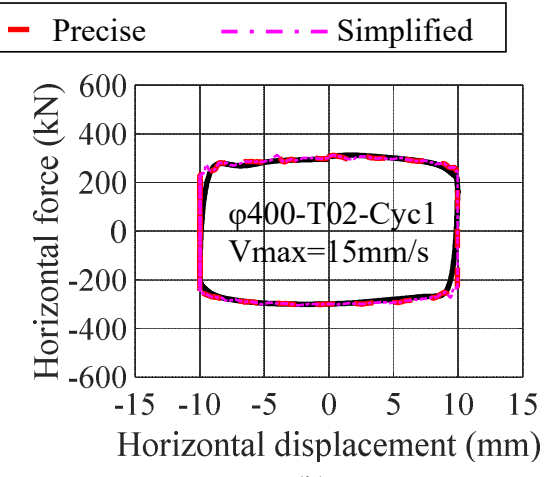

(b)

Figure 6. Accuracy of the precise and simplified models under (a) strong excitation (seismic) and (b) weak excitation (wind-like).

\subsection{Numerical Results Using a Constant Friction Coefficient}

In order to find the constant friction coefficient that was suitable for the most amount of time during most seismic situations, a nominal friction coefficient, $\mu_{n}$, was defined. The value of $\mu_{n}$ was 0.043 for both sizes of the sliders based on experimental results, and it represented the nominal friction coefficient under seismic load conditions. This value was determined by taking the average of the friction coefficient of the DCFPB at zero displacement points in the second cycle (points $\mathrm{c}$ and $\mathrm{d}$ in Figure 7) of the input sine wave with a constant pressure of $60 \mathrm{~N} / \mathrm{mm}^{2}$ and a maximum velocity of $400 \mathrm{~mm} / \mathrm{s}$ (T01 of the dependency test in Table 1).

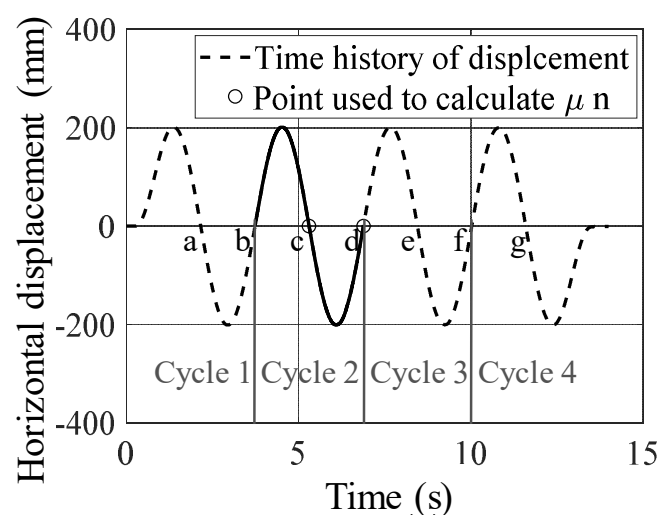

Figure 7. Experimental data used to obtain $\mu_{n}$.

The accuracy of using $\mu_{n}$ under strong excitation and weak excitation is shown in Figure 8. The results showed that $\mu_{n}$ was suitable for strong excitations but could not be used under weak excitations. In the other tests in Table 2, which can all be considered to be strong excitations, the simulations using $\mu_{n}$ all showed that the force-deflection relations of the DCFP bearings had no large differences [19]. Therefore, the constant friction coefficient, $\mu_{n}$, could be applied for the rough behavior estimation of DCFP bearings under seismic loads. For example, it could be applied for the response force simulation when the response displacement of the bearing is known.

In the numerical simulation of DCFP bearings, pressure, velocity and temperature dependencies all have influence on the behavior of the bearings. However, for DCFP bearings under stable pressure, the temperature variation caused by friction heating will dominate the influence. This influence is more obvious when the temperature is relatively low (e.g., $20-100^{\circ} \mathrm{C}$ ), meaning that it is under weak excitations, as shown in Figures $6 \mathrm{~b}$ and $8 \mathrm{~b}$. However, when the temperature is higher, the influence will ease up, as shown in Figures 6a and 8a, and this is the reason why the constant friction coefficient can be applied for rough estimation under strong excitations such as seismic loads. 


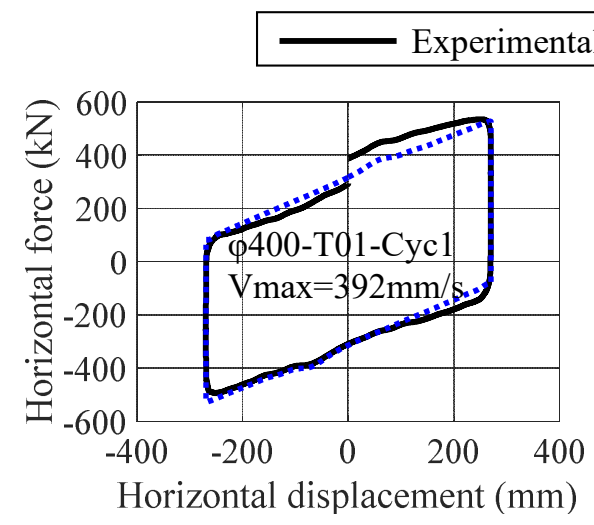

(a)

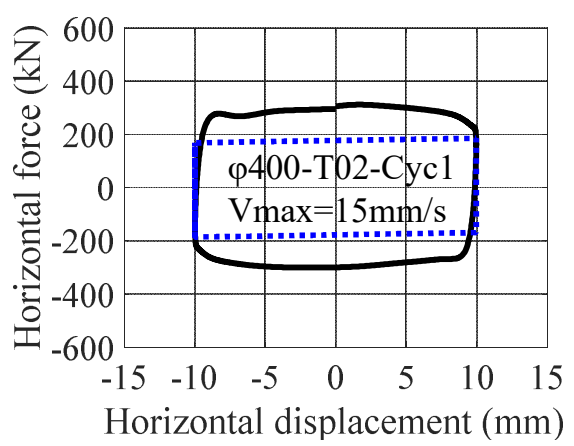

(b)

Figure 8. Accuracy of using $\mu_{n}$ under (a) strong excitation (seismic) and (b) weak excitation (wind-like).

\section{Numerical Analyses of the Dynamic Response of Isolated Structures}

\subsection{Mechanical Model}

The mechanical model used in this study is shown in Figure 9 and considered both static and dynamic friction [20]. To demonstrate the relation of the response of the isolation layer and the earthquake records more clearly, the upper structure is set as a rigid body.

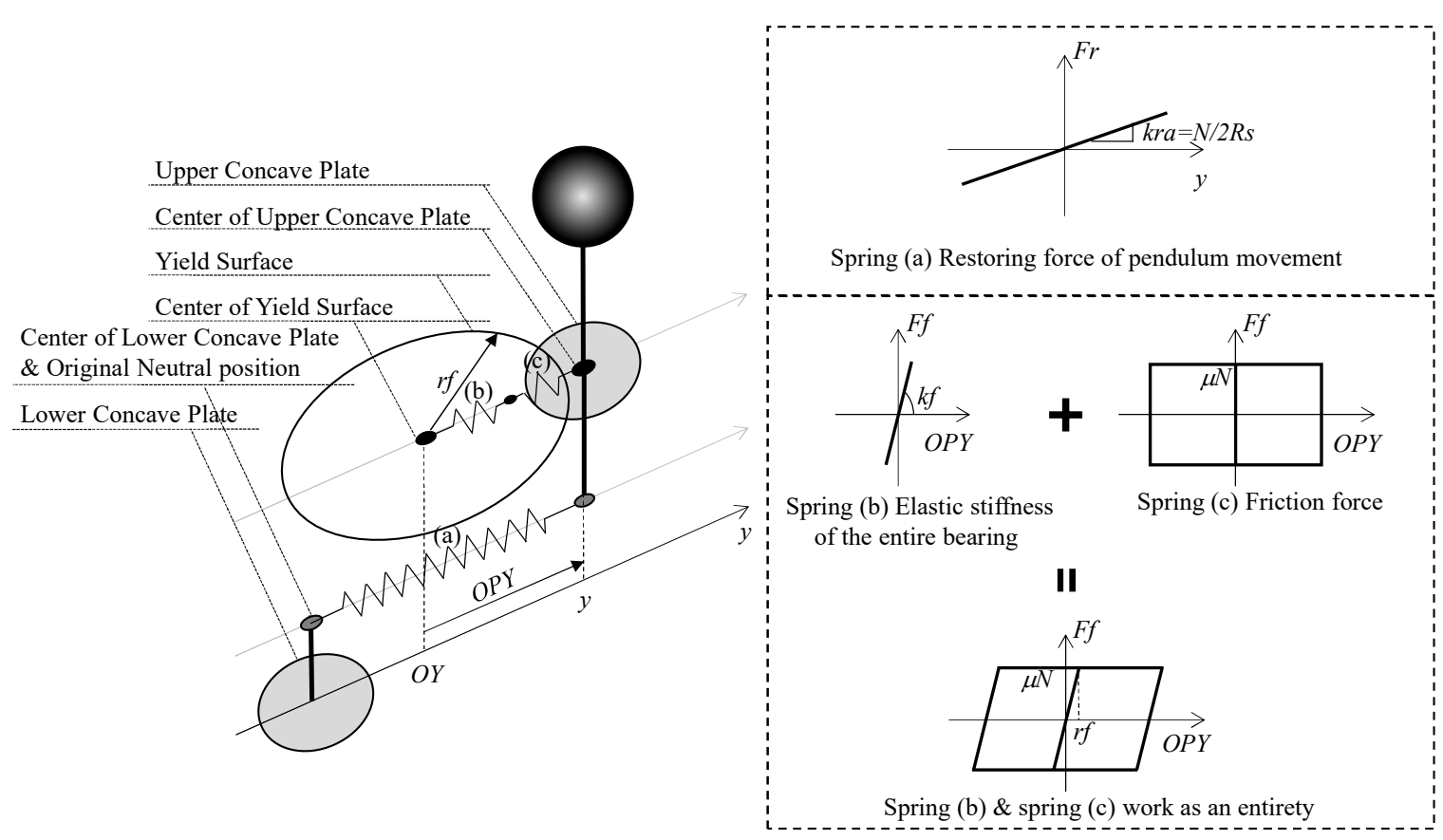

Figure 9. Unidirectional mechanical model of a rigid structure with DCFP bearings.

In Figure 9, the center of the lower concave plate is taken as the original neutral position. The stiffness of the upper structure is considered to be infinite in order to make the behavior of the DCFP bearing clearer. Whether sliding between the slider and the concave plate will occur or not is considered by a yield surface with a radius $r_{f}$ [21,22]. OY is the center of the yield surface, $y$ is the displacement of the upper structure relative to the center of the lower concave plate and OPY is the distance from OY to $y$. The internal forces of the DCFP bearing are considered in terms of three springs: spring (a), spring (b) and spring (c). Spring (a) represents the restoring force of the pendulum movement. $k_{r a}$ is the stiffness, $N$ is the vertical force that acts on the DCFP bearing, and $R_{s}$ is the 
spherical radius of the upper and lower concave plates. In this study, the DCFP bearings with slider diameters equal to $400 \mathrm{~mm}$ and $R_{s}$ values equal to $4500 \mathrm{~mm}$ are set, and a vertical load that can provide $60 \mathrm{MPa}$ of pressure on the slider surface is applied. Therefore, $k_{r a}$ equals $0.838 \mathrm{kN} / \mathrm{mm}$. Spring (b) represents the elastic stiffness of the entire DCFP bearing with a value of $k_{f}=1900 \mathrm{kN} / \mathrm{mm}$, based on experimental results. Spring (c) represents the friction force between the slider and two concave plates. Spring (b) and spring (c) work entirely to simulate the friction force. The friction force is represented by spring (b) when there is no sliding and by the friction models, introduced in Section 2, during sliding.

\subsection{Input Ground Motions}

In order to see whether the simplified model could be used instead of the precise model in the response analysis and later as the analysis database for the prediction method, the earthquake inputs shown in Table 3 were selected. These inputs include earthquake records with various intensities, various durations and both near and far fields. Additionally, in order to study the behavior of the isolation system under earthquakes with similar intensities, each earthquake record was amplified to four input waves with PGVs (Peak Ground Velocities) equal to $0.25,0.50,0.75$ and $1.00 \mathrm{~m} / \mathrm{s}$. In Table 3, the first column shows the abbreviation of the earthquake record, which is consist of the name and the measuring station of the earthquake.

Table 3. Input earthquake motion.

\begin{tabular}{cccccc}
\hline Abv. & Earthquake & Station & PGV (m/s) & Duration (s) & Field \\
\hline JKB & Kobe & JMA Kobe & 0.893 & 30 & Far \\
KNA & Kobe & Nishi-Akashi & 0.373 & 41 & Near \\
TC1 & Chi-Chi & TCU129 & 0.554 & 90 & Near \\
NCC & Northridge & Canyon Country-WLC & 0.449 & 20 & Far \\
LPG & Loma Prieta & Gilroy Array & 0.447 & 40 & Near \\
IVD & Imperial Valley & Delta & 0.330 & 100 & Near \\
TSD & Tohoku & JMA Sendai & 0.545 & 180 & Near \\
TIM & Tohoku & JMA Ishinomaki & 0.376 & 300 & Near \\
\hline
\end{tabular}

\subsection{Accuracy of the Simplified Model}

As shown in Figure 10, the response analysis results using the simplified model were as good as those using the precise model under both strong and weak earthquake excitations. This was because, in both cases, the slider was on the monitoring point of the simplified model for most of time. In the response analysis of all the other input waves introduced in Table 3, the response analysis results using the simplified model could always provide results with similar accuracy to those obtained using the precise model. Thus, the simplified model was used in the response analysis instead of the precise model in order to save time.

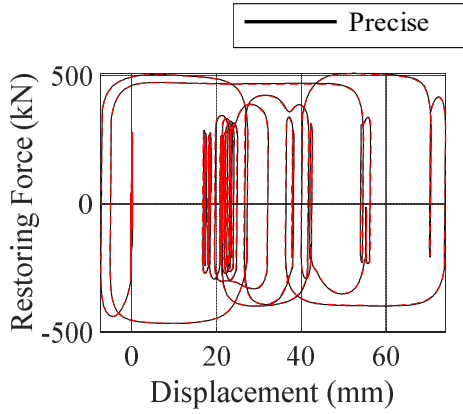

(a)

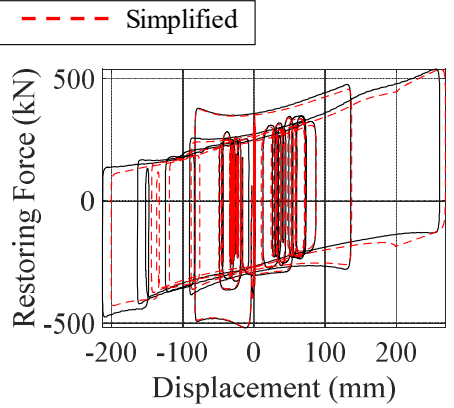

(b)

Figure 10. Accuracy of the force displacement curve using the simplified model under JKB (Kobe earthquake measured by JMA Kobe station): (a) PGV $=0.25 \mathrm{~m} / \mathrm{s}$; (b) PGV $=1.0 \mathrm{~m} / \mathrm{s}$. 


\subsection{Relation between Maximum Response Displacement and PGV}

Based on the simulation results, the relationship between the maximum response displacement of the isolation layer $\left(y_{\max }\right.$, which is the maximum relative displacement between the upper concave plate and the lower concave plate) and the peak ground velocity (PGV) of the input earthquake is shown in Figure 11. It can be seen that, even though they have the same PGV, different earthquake inputs can still cause different $y_{\max }$. The difference may be caused by other earthquake characteristics such as the ground acceleration and the bearing's friction coefficient during excitation. These factors are also related to the transfer of the input energy in the isolation layer. The relationship between them will be studied in the next chapter.

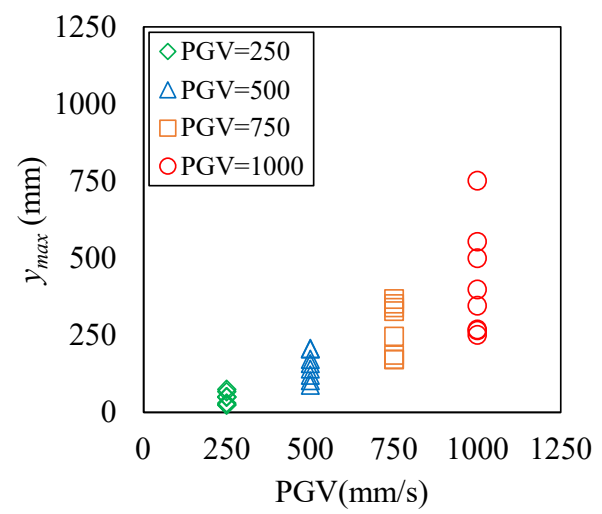

Figure 11. Relationship between the maximum response displacement of the isolation layer and the peak ground velocity under unidirectional earthquake inputs.

\section{Proposed Prediction Method}

A simple method is proposed in this chapter to predict the response of an isolation system under a certain unidirectional earthquake input and the energy transfer during a process based solely on the earthquake record. Furthermore, the method was simplified and optimized based on the response analysis results. Finally, how this method could be applied to general design factors was also studied.

\subsection{Mechanical Model}

6.1.1. Relationship between Ground Velocity, the Response Displacement and the Input Energy of the Isolation Layer.

By using the model in Figure 9, the relative movement and the energy balance in a base-isolated building become the relative movement and the energy balance in the base-isolated layer.

As one matter of concern during the design stage, the prediction of the maximum relative displacement between the upper and lower concave plates of the bearing during earthquakes is the focus of this study. Figure 12 shows the relative movement of the base-isolated layer during strong earthquake pulses, where $v u$ is the absolute velocity of the upper structure, $v g$ is the absolute velocity of the ground, and $y$ shows the relative displacement between the upper and lower concave plates, which can also be called the response displacement of the isolation layer. Then, the response velocity of the isolation layer (the relative velocity between the upper and lower concave plates) can be expressed as:

$$
v=\dot{y}=v u-v g
$$

During a strong earthquake pulse, the history of $v g$ is known and the value of $v u$ is mainly determined by the dynamic friction coefficient of the bearing. Therefore, $y$ can be predicted by integral $v$, which is the difference between $v u$ and $v g$. 


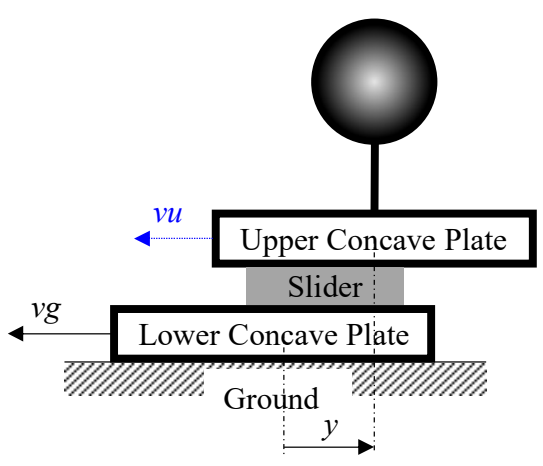

Figure 12. Relative movement of the base-isolated layer.

Based on the response analysis results, the ground velocity record of the earthquake was found to be greatly related to, and work simultaneously with, the transferred energy and the response displacement of the isolation layer during earthquakes. As shown in Figure 13, during one earthquake, several large velocity pulses (from one ground peak velocity, $v g_{i-1}$, to the next peak, $v g_{i}$, and to the next peak, $v g_{i+1}$, is one velocity pulse) exist. The difference between $v g_{i-1}$ and $v g_{i}$ was defined as the velocity difference of this velocity pulse, $\Delta v g_{i}$, which could show the intensity of the velocity pulse:

$$
\Delta v g_{i}=v g_{i}-v g_{i-1}
$$

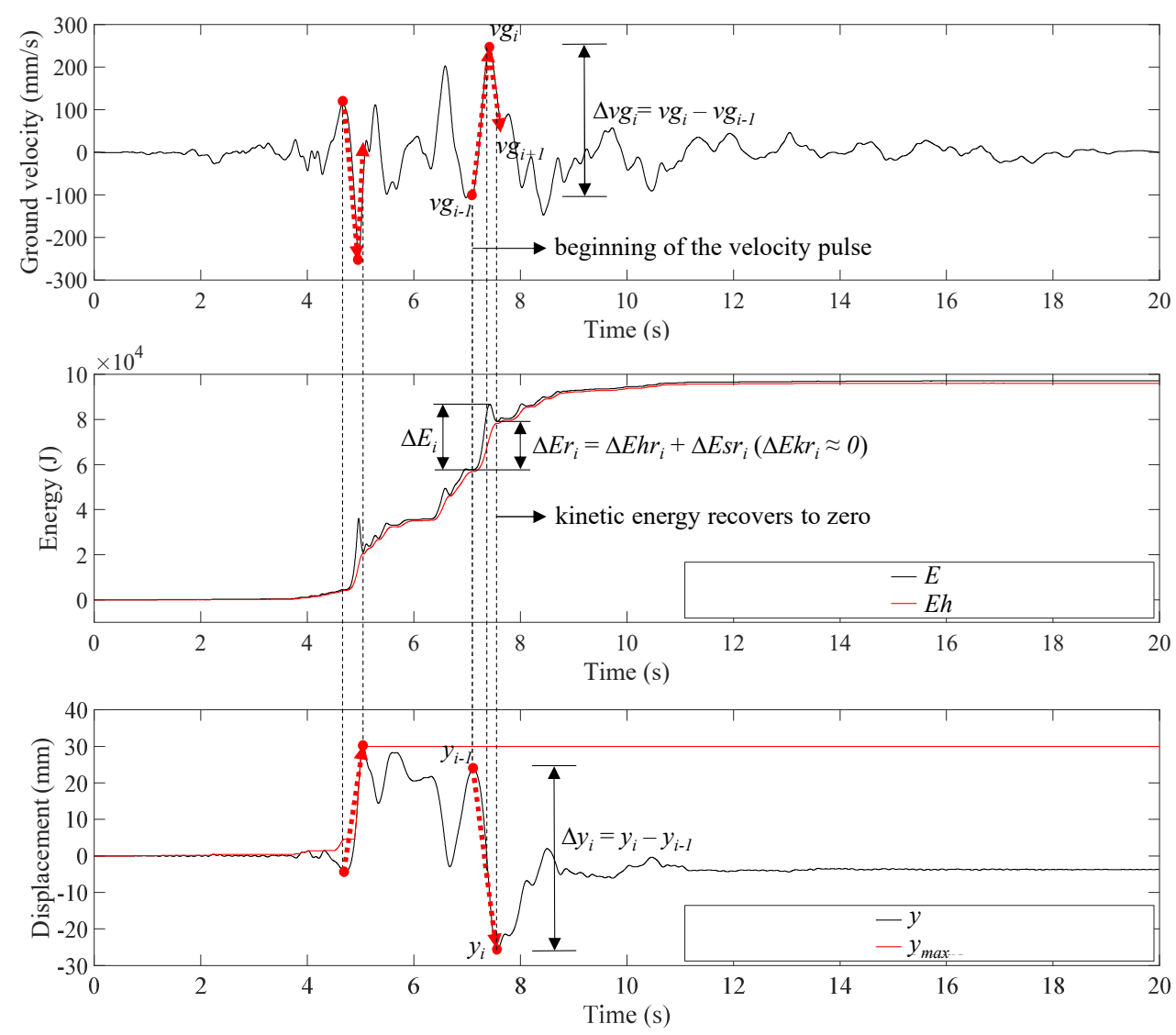

Figure 13. Time history of ground velocity, input energy and response displacement of the base-isolated layer during NCC (Northridge earthquake measured by Canyon Country-WLC station) with its PGV equals to $250 \mathrm{~mm} / \mathrm{s}$. 
It was found that, when a large $\Delta v g_{i}$ exists in the earthquake, it will lead to large input energy in the structural system, $\Delta E_{i}$, and a large response displacement of the isolation layer (a large relative displacement between the upper concave plate and the lower concave plate), $\Delta y_{i}$, simultaneously. Since the upper structure is considered to be a rigid body in this study, the total input energy, $E$, is consumed by the hysteresis energy $E_{h}$. However, during a velocity pulse, some of the input energy will first be temporarily stored in the kinetic energy, $E_{k}$, and the elastic strain energy, $E_{s}$. In order to eliminate the interference of $E_{k}$, the change in energy from the beginning of the velocity pulse to the time kinetic energy recovers to zero, which is approximately the time interval from $y_{i-1}$ to $y_{i}$ and is considered to be very useful as it is related to the peak response displacement change, $\Delta y_{i}$. In Figure 13, $y_{i}$ and $y_{i-1}$ are two neighboring peak response displacements of the isolation layer, and every time a peak response displacement is achieved, $E_{k}$ becomes zero; $y_{\max }$ is the maximum amplitude of the response displacement of the isolation layer; $\Delta y_{i}$ is one of the peak response displacement changes of the isolation layer, and the one shown in the figure is the maximum. Then, in this time interval, the total input energy, $\Delta E r_{i}$, can be expressed as the sum of the consumed energy. $\Delta E h r_{i}$ and the change in the elastic strain energy, $\Delta E s r_{i}$, with the change in kinetic energy, $\Delta E k r_{i}$, were also considered to be zero:

$$
\Delta E r_{i}=\Delta E h r_{i}+\Delta E s r_{i} \quad\left(\Delta E k r_{i}=0\right)
$$

Since the elastic strain energy was also relatively small in this study, the value of it could be ignored under large velocity pulses. Then, $\Delta E r_{i}$ in this time interval can be expressed as:

$$
\Delta E r_{i}=\Delta E h r_{i}
$$

To see exactly how the ground velocity record determines the response displacement of the isolation layer, the velocity history of the upper structure, $v u$, and the ground, $v g$, based on the response analysis, is shown in Figure 14, where, based on Equation (13), the area between the velocity history of the upper structure and the ground is the response displacement of the isolation layer. It can be seen from the time history of $v u$ that the acceleration of the upper structure during large velocity pulses is roughly constant. Therefore, in the prediction, it is reasonable to consider the friction coefficient during large velocity pulses to be constant.

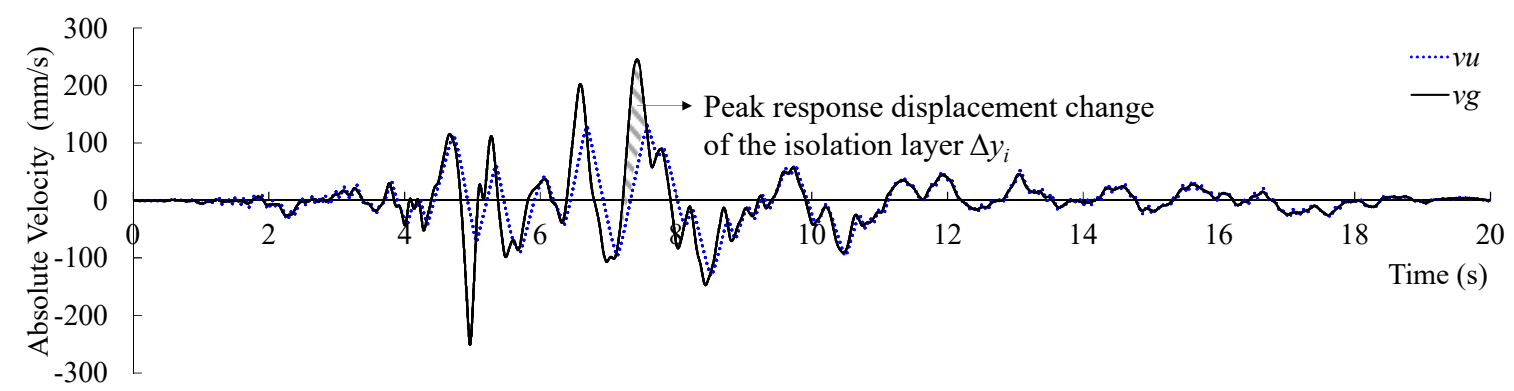

Figure 14. Time history of the ground velocity and upper structure velocity during earthquakes where the NCC and PGV are equal to $250 \mathrm{~mm} / \mathrm{s}$.

In Figure 15, the same response displacement is shown in the time history of the response velocity of the isolation layer, $v$. 


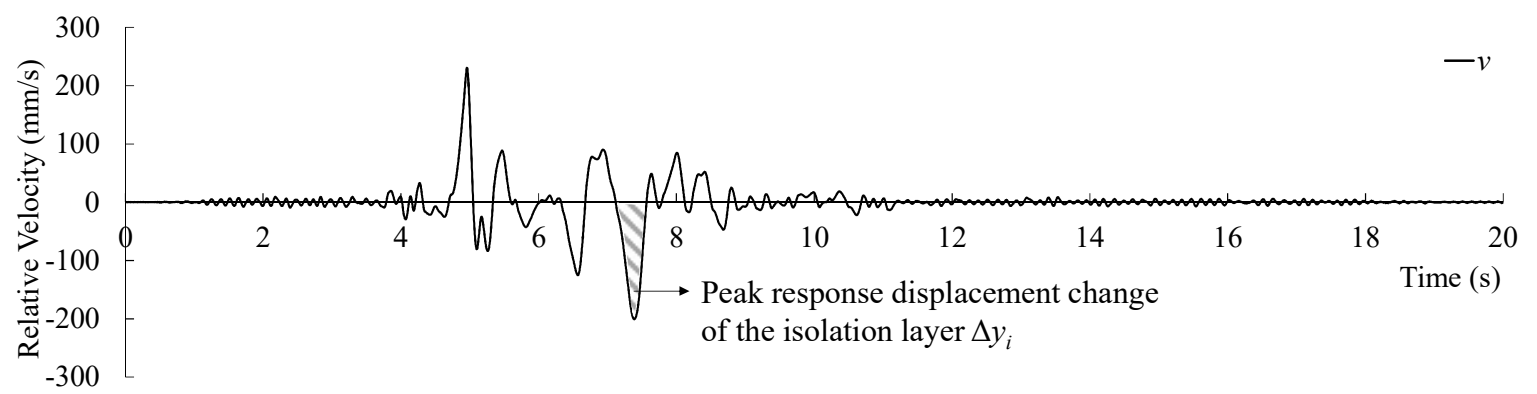

Figure 15. Time history of the relative velocity between the upper and lower concave plates during earthquakes where the NCC with PGV are equal to $25 \mathrm{~mm} / \mathrm{s}$.

\subsubsection{Prediction of the Response Displacement of the Isolation Layer}

In this section, the peak response displacement changes in the isolation layer, $\Delta y_{i}$, were primarily predicted by simplifying Figure 14. It should be mentioned that $\Delta y_{i}$ was predicted instead of $y_{\max }$. This was because the value of $y_{\max }$ was highly related to former response displacement, which made it difficult to be derived theoretically. However, the derivation of $\Delta y_{i}$ was more related to the corresponding velocity pulse. Furthermore, since the maximum $\Delta y_{i}$ was usually larger than $y_{\max }$, the maximum $\Delta y_{i}$ could be considered to be a conservative value of $y_{\max }$.

As shown in the left figure of Figure 16, the solid line shows a ground velocity pulse from $v g_{i-1}$ to $v g_{i}$ to $v g_{i+1}$ and the two dashed lines show the slope from $v g_{i-1}$ to $v g_{i}$ and the slope from $v g_{i}$ to $v g_{i+1}$, respectively, which can be understood as the average ground acceleration. The dotted line is the absolute velocity of the upper structure, and its slope can be roughly considered to be constant, as introduced in Figure 14. Furthermore, since the points where $v u$ and $v g$ intersect are determined by the former velocity history, the intersection in the left figure of Figure 16 was randomly picked between $v g_{i-1}$ and $v g_{i}$, referred to as $v u_{i-1}$. At the intersection points, vu was equal to vg, which meant that $v$ was equal to zero, and this meant that the direction of the response displacement of the isolation layer, $y$, would change from the next second. Then, until the next intersection, $y$ would be in the same direction; reach the peak displacement change, $\Delta y_{i}$; and reverse direction again. Then, how the calculation of $\Delta y_{i}$ can be simplified under a large velocity pulse is shown in the right figure of Figure 16. In the simplification, $v u_{i-1}$ and $v g_{i-1}$ are assumed to be equal, which is a conservative assumption for predicting $\Delta y_{i}$ :

$$
v u_{i-1}=v g_{i-1}
$$
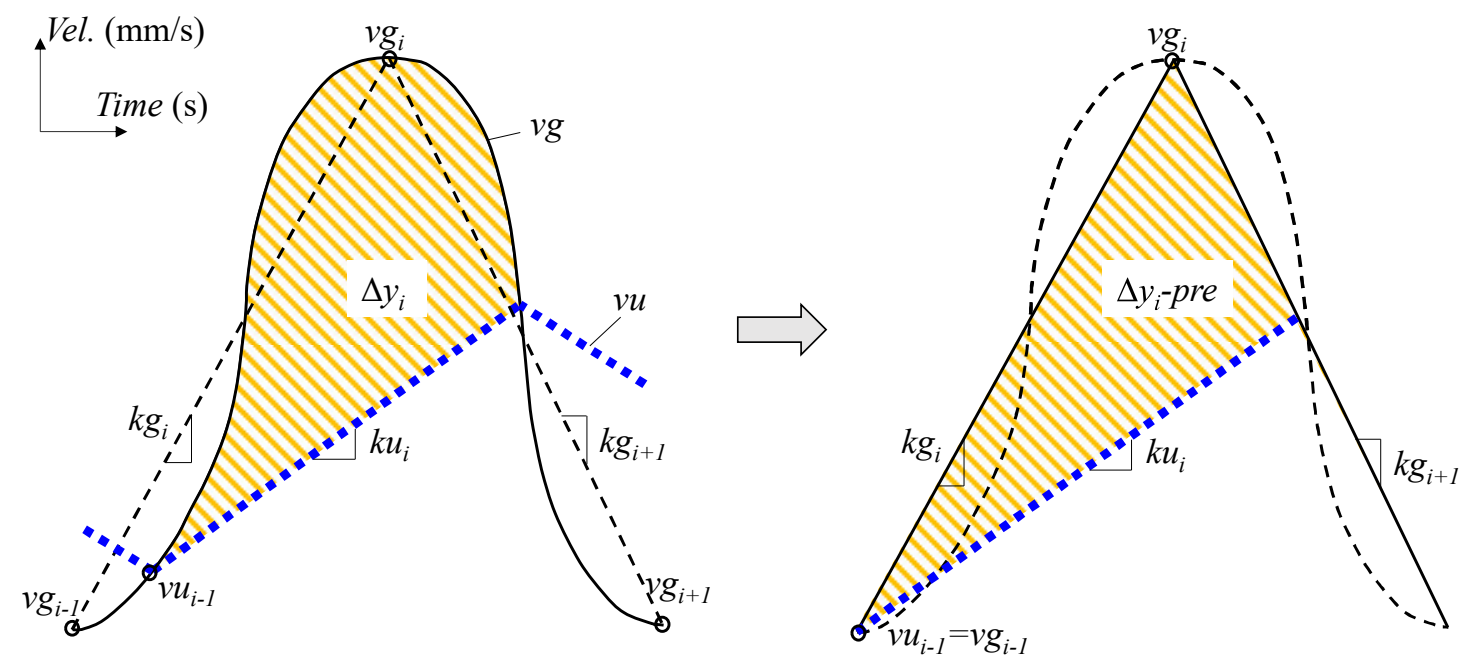

Figure 16. Method to predict the response displacement of the isolation layer $\left(0<k u_{i} / k g_{i}<0.8\right)$. 
The acceleration between two adjacent peak ground velocities is assumed to be the average value, $k g_{i}$ and $k g_{i+1}$ :

$$
k g_{i}=\frac{v g_{i}-v g_{i-1}}{\Delta t_{i}} ; \quad k g_{i+1}=\frac{v g_{i+1}-v g_{i}}{\Delta t_{i+1}}
$$

where $\Delta t_{i}$ is the time interval between $v g_{i-1}$ and $v g_{i} ; \Delta t_{i+1}$ is the time interval between $v g_{i}$ and $v g_{i+1}$.

The friction coefficient was assumed to be the nominal friction coefficient, $\mu_{n}$, which was equal to 0.043 and could be used to roughly simulate the behavior of the bearing under earthquake excitations. Therefore,

$$
k u_{i}=\mu_{n} \times g \times k g_{i} /\left|k g_{i}\right|
$$

where $g$ is the gravity acceleration in $\mathrm{mm} / \mathrm{s}^{2}$.

Then, the predicted value will be $\Delta y_{i}$-pre, as shown in Figure 16, which is the predicted peak response displacement of the isolation layer.

It can be seen from Figure 16 that, when the value of $k u_{i}$ is close to $k g_{i}, \Delta y_{i}$-pre is close to zero. However, based on the response analysis results, $\Delta y_{i}$ can also be relatively large in this situation. Therefore, a special prediction method was proposed for these cases, as shown in Figure 17, in which the case of $k u_{i} / \mathrm{kg}_{i}$ being equal to 1.0 is shown. Based on the response analysis results, the cases of $k u_{i} / \mathrm{kg}_{i}$ being between 0.8 and 1 should use this method and the cases of $k u_{i} / \mathrm{kg}_{i}$ being between 0 and 0.8 should use the method in Figure 16.
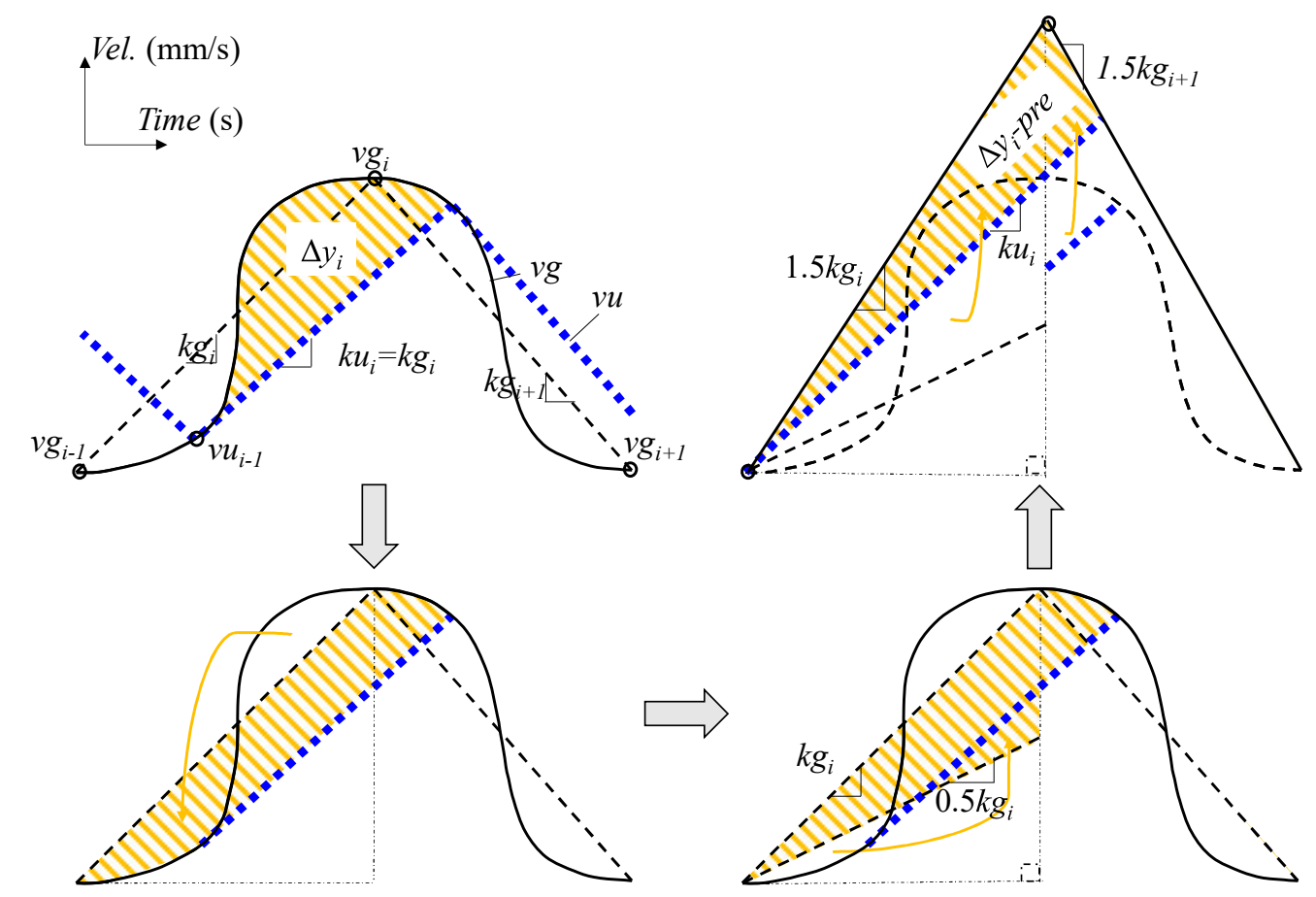

Figure 17. Method to predict the response displacement of the isolation layer $\left(0.8<k u_{i} / k g_{i} \leq 1.0\right)$.

Therefore, as shown in the right half of Figure 16, for the cases of $k u_{i} / \mathrm{kg}_{i}$ being between 0 and 0.8 , $\Delta y_{i}$-pre (the predicted value of the peak response displacement change of the isolation layer) can be predicted by $v g_{i-1}, v g_{i}, \mathrm{~kg}_{i}, \mathrm{~kg}_{i+1}$ and $k u_{i}$, which are given by the time history data of the earthquake record and Equation (19).

$$
\begin{aligned}
\Delta y_{i}-p r e & =-\frac{1}{2} \times\left(k g_{i}-k u_{i}\right) \times\left(\frac{v g_{i}-v g_{i-1}}{k g_{i}}\right)^{2} \times\left(1+\frac{k g_{i}-k u_{i}}{k u_{i}-k g_{i+1}}\right) \\
& =-\frac{\left(k g_{i}-k u_{i}\right) \times\left(k g_{i}-k g_{i+1}\right)}{2 \times k g_{i} \times\left(k u_{i}-k g_{i+1}\right)} \times\left(v g_{i}-v g_{i-1}\right)^{2}
\end{aligned}
$$


As for the cases of $k u_{i} / \mathrm{kg}_{i}$ being between 0.8 and 1 , the value of $v g_{i-1}, v g_{i}, k g_{i}$ and $k g_{i+1}$ should be amplified by 1.5 before using Equation (20).

The accuracy was between 1 and 2.1, as shown in Figure 18, which is a conservative prediction with an error caused by the assumptions shown in Equations (17)-(19).

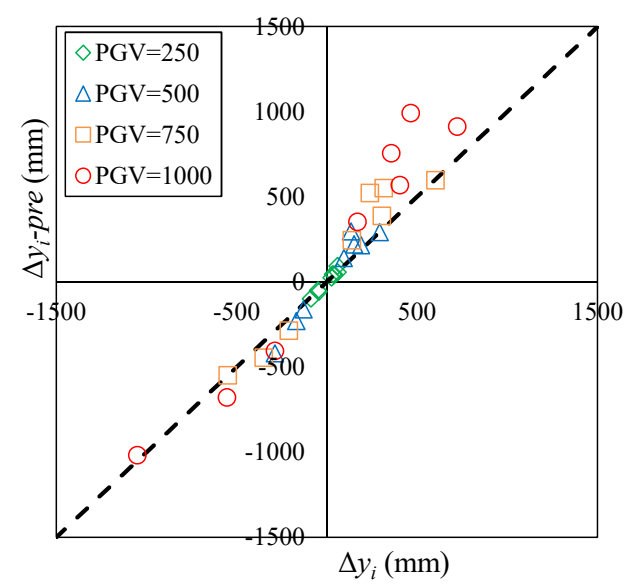

Figure 18. Accuracy of the prediction method for the maximum response displacement change of the isolation layer under selected earthquake inputs.

\subsubsection{Prediction of Energy Transfer}

The input energy of the isolation layer was defined by Equation (4) in the introduction. Since the response displacement of the isolation layer, $y$, can be predicted, the total input energy to the isolation layer between $v g_{i-1}$ and $v g_{i}$ can also be predicted by $v g_{i-1}, v g_{i}, k g_{i}, k g_{i+1}$ and $k u_{i}$, which were given by time history data of the earthquake records and Equation (19):

$$
\begin{aligned}
\Delta E_{i}-\text { pre } & =m \times k g_{i} \times \frac{1}{2} \times\left(k g_{i}-k u_{i}\right) \times\left(\frac{v g_{i}-v g_{i-1}}{k g_{i}}\right)^{2} \\
& =\frac{1}{2} \times m \times\left(1-\frac{k u_{i}}{k g_{i}}\right) \times\left(v g_{i}-v g_{i-1}\right)^{2}
\end{aligned}
$$

The equivalent velocity [9] of the total input energy is:

$$
V_{\Delta E_{i}}-\text { pre }=\sqrt{1-\frac{k u_{i}}{k g_{i}}} \times\left|v g_{i}-v g_{i-1}\right|
$$

The amount of $\Delta E_{i}$ consumed by the hysteresis energy, $\Delta E_{i}$, can be predicted by $v g_{i-1}, v g_{i}, \mathrm{~kg}_{i}$, $k g_{i+1}$ and $k u_{i}$, which were given by the time history data of the earthquake records and Equation (19):

$$
\begin{aligned}
\Delta E h r_{i}-p r e & =m \times k u_{i} \times \Delta y_{i}-p r e \\
& =\Delta E_{i}-p r e \times \frac{k u_{i} \times\left(k g_{i}-k g_{i+1}\right)}{k g_{i} \times\left(k u_{i}-k g_{i+1}\right)}
\end{aligned}
$$

The equivalent velocity of the consumed energy is:

$$
V_{\Delta E h r_{i}}-\text { pre }=\sqrt{1-\frac{k u_{i}}{k g_{i}}} \times\left|v g_{i}-v g_{i-1}\right| \times \sqrt{\frac{k u_{i} \times\left(k g_{i}-k g_{i+1}\right)}{k g_{i} \times\left(k u_{i}-k g_{i+1}\right)}}
$$

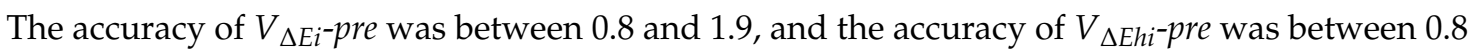
and 1.6. It can be seen that this prediction method is relatively conservative. 


\subsection{Simplification and Optimization of the Prediction Method Based on the Analysis Results}

\subsubsection{Simplification of $\mathrm{kg}_{i+1}$}

By combining Equations (21) and (23), Equation (20) can be expressed in the form of energy as:

$$
m \times k u_{i} \times \Delta y_{i}-p r e=\frac{1}{2} \times m \times\left(1-\frac{k u_{i}}{k g_{i}}\right) \times\left(v g_{i}-v g_{i-1}\right)^{2} \times \frac{k u_{i} \times\left(k g_{i}-k g_{i+1}\right)}{k g_{i} \times\left(k u_{i}-k g_{i+1}\right)}
$$

$\mathrm{kg}_{i+1}$ was only contained in the rightmost fraction of Equation (25), which can be considered as the percentage of energy absorption, and it was attempted to simplify this fraction in order to not only simplify the equation but also make the method easier to apply in the design stage. Therefore, it is generalized with a generalization parameter, $\varepsilon$ :

$$
k g_{i+1}=-\varepsilon \times k g_{i}
$$

Then, the predicted percentage of the absorption can be expressed, in the form of equivalent velocity of energy, as:

$$
\frac{V_{\Delta E h r_{i}}-\text { pre }}{V_{\Delta E_{i}}-\text { pre }}=\sqrt{\frac{k u_{i} \times\left(k g_{i}-k g_{i+1}\right)}{k g_{i} \times\left(k u_{i}-k g_{i+1}\right)}}=\sqrt{\frac{(1+\varepsilon) \times \frac{k u_{i}}{k g_{i}}}{\varepsilon+\frac{k u_{i}}{k g_{i}}}}
$$

By comparing the prediction value of Equation (27) to the analysis result points, as shown in Figure $19,0.25$ is considered to be the most suitable value of $\varepsilon$ for the general calculation. It should be mentioned that, since the percentage of absorption will not exceed one, the value of $V_{\Delta E h r i}-$ pre $/ V_{\Delta E i}$-pre can be taken as one when $k u_{i} / \mathrm{kg}_{i}$ is larger than one.

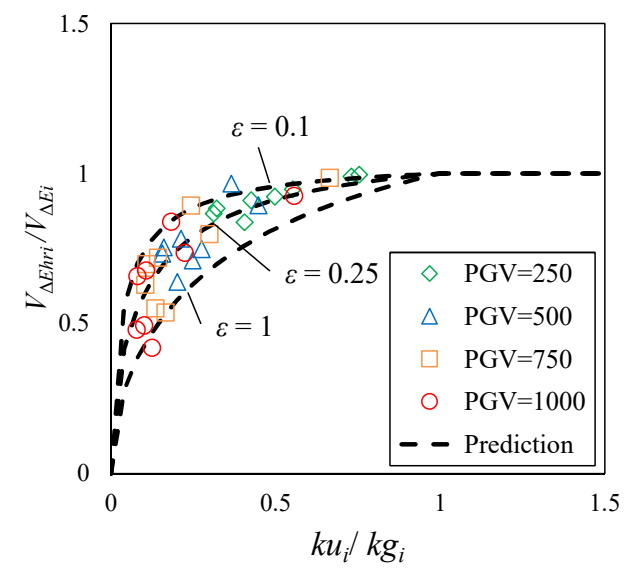

Figure 19. Simplified prediction of the percentage of absorption by assuming different values of $\varepsilon$.

\subsubsection{Simplification of the Prediction Equation of $V_{\Delta E i}$-pre}

Equation (22) gives the prediction equation of $V_{\Delta E i}$-pre. It shows a linear relationship between $V_{\Delta E i}$-pre and the absolute value of the peak ground velocity difference, $\left|\Delta v g_{i}\right|$, which equals to $\left|v g_{i}-v g_{i-1}\right|$. By observing the relationship between the analysis results for $V_{\Delta E i}$ and $\left|\Delta v g_{i}\right|$, as shown in Figure 20, it was found that the value of $\mathrm{kg}_{i}$ could be taken as a constant without causing large differences.

Therefore, the slope of the prediction line, based on Equation (22), is determined as:

$$
\frac{V_{\Delta E_{i}}-\text { pre }}{\left|\Delta v g_{i}\right|}=\sqrt{1-\frac{k u_{i}}{k g_{i}}} \approx \sqrt{1-\frac{k u_{i}}{k g_{\text {ave }}}}=\sqrt{1-\frac{\left|k u_{i}\right|}{930}}
$$


where the $k g_{\text {ave }}=$ average value of $k g_{i}$ (the $\mathrm{kg}_{i}$ corresponding to the maximum response displacement of the isolation layer) of the eight selected earthquakes with the PGV amplified as $250 \mathrm{~mm} / \mathrm{s}^{2}$, which was $930 \mathrm{~mm} / \mathrm{s}^{2}$. The value $930 \mathrm{~mm} / \mathrm{s}^{2}$ can be considered to be a constant value that can be used in most cases where the input earthquakes have PGVs larger than $250 \mathrm{~mm} / \mathrm{s}^{2}$, because the eight earthquakes selected in this study were considered to be representative.

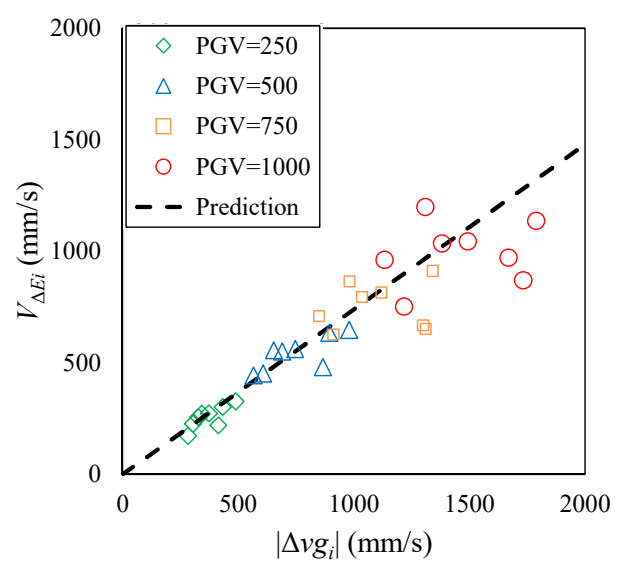

Figure 20. Simplified prediction of $V_{\Delta E i}$.

\subsubsection{Simplified and Optimized Prediction Method}

By applying Equations (27) and (28), the proposed prediction method can be simplified, as shown in Figure 21.
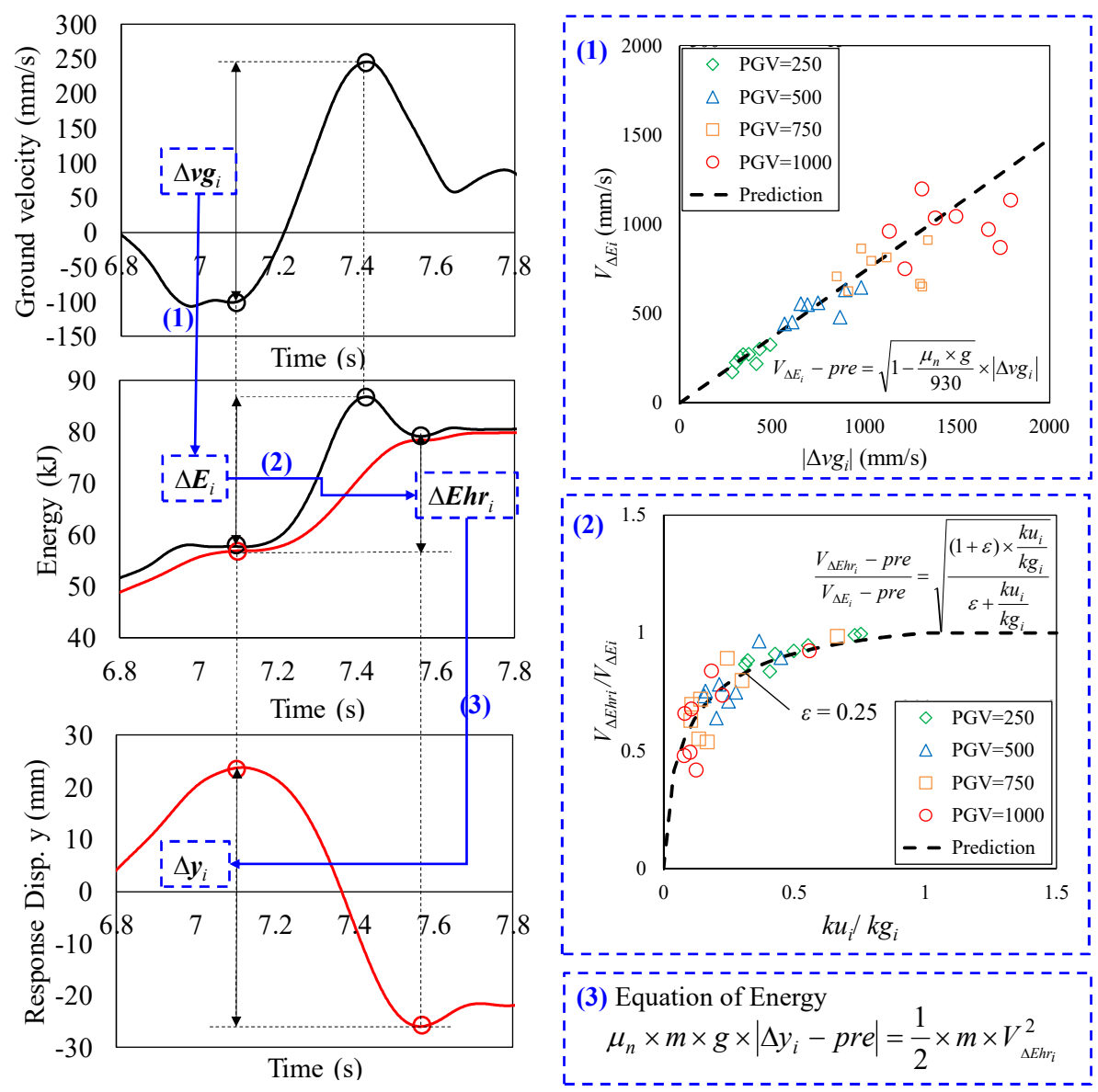

Figure 21. Simplified prediction method. 
The accuracies of $V_{\Delta E i}$-pre, $V_{\Delta E h r i}$-pre and $\Delta y_{i}$-pre when using this simplified prediction method are shown in Figures 22-24, respectively. The accuracy of $V_{\Delta E i}$-pre was between 0.8 and 1.5, the accuracy of $V_{\Delta E \text { hri }}$-pre was between 0.7 and 1.6, and the accuracy of $\Delta y_{i}$-pre was between 0.7 and 1.8.

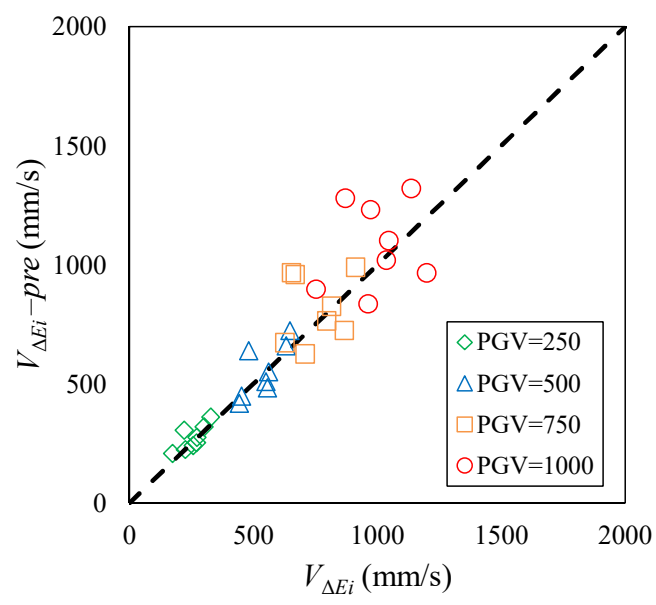

Figure 22. Accuracy of the simplified prediction method for $V_{\Delta E i}$.

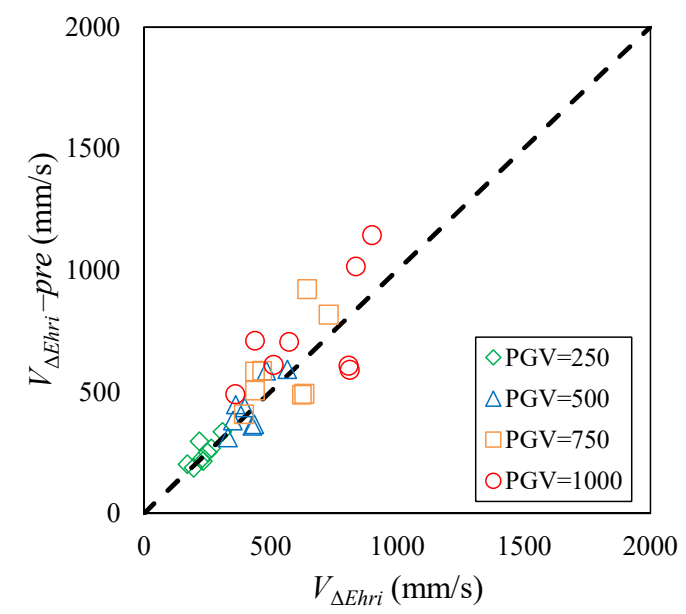

Figure 23. Accuracy of the simplified prediction method for $V_{\Delta E h r i}$.

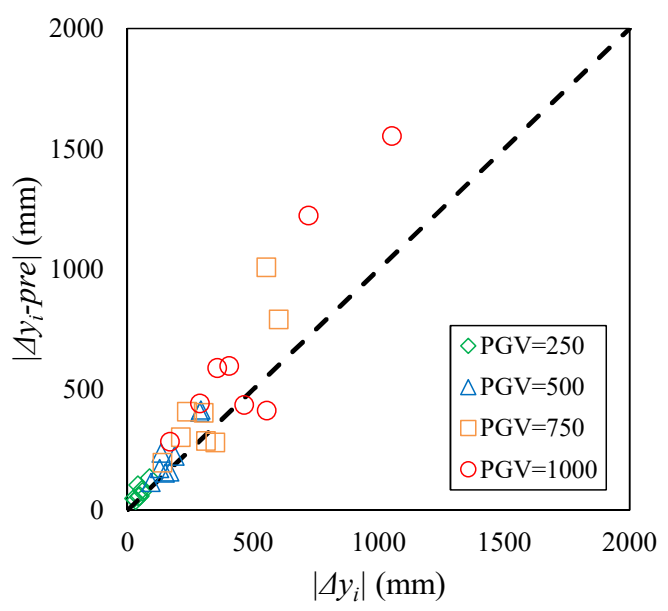

Figure 24. Accuracy of the simplified prediction method for $\left|\Delta y_{i}\right|$. 


\subsection{Application of the Prediction Method in Design}

In order to give a general prediction of the maximum response displacement change and input energy of an isolation layer under a group of earthquakes with a certain intensity, the specific earthquake characteristics, such as $\Delta v g_{i}$ and $k g_{i}$, should be replaced. Therefore, Equation (29) is proposed, where $\zeta$ is the generalization parameter of the ground velocity. As shown in Figure 25, based on the earthquake records, $\left|\Delta v g_{i}\right|$ was assumed to be 1.5 times the peak ground velocity (PGV) in this study.

$$
\left|\Delta v g_{i}\right|=\varsigma \times P G V
$$

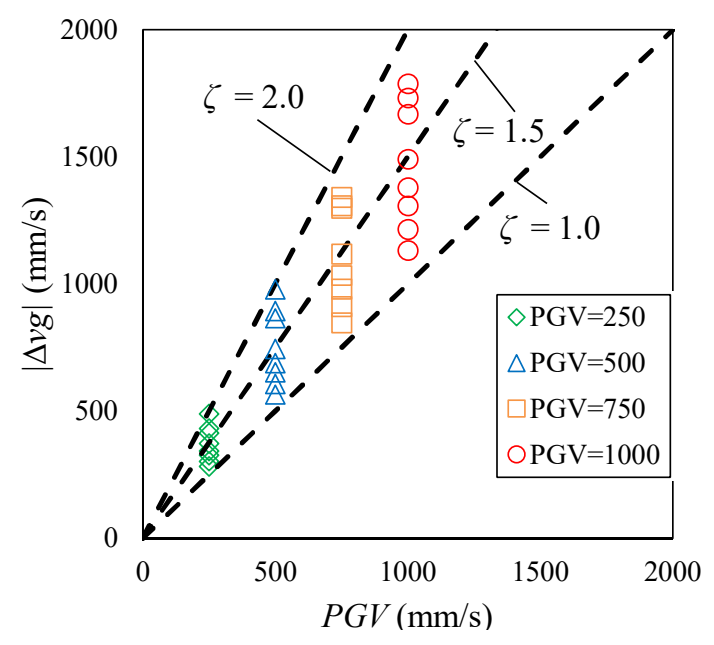

Figure 25. Relationship between $|\Delta v g|$ and PGV.

$k g_{i}$ was assumed based on the average value of $\mathrm{kg}_{i}$ of the eight selected earthquakes with PGVs amplified to $250 \mathrm{~mm} / \mathrm{s}$, which was $930 \mathrm{~mm} / \mathrm{s}$ :

$$
k g_{i}=930 \times \frac{P G V}{250}
$$

Therefore, the prediction method can be generalized as:

$$
\begin{gathered}
V_{\Delta E_{i}}-\text { pre }=\sqrt{1-\frac{\mu_{n} \times g}{930}} \times \varsigma \times P G V \\
V_{\Delta E h r_{i}}-\text { pre }=V_{\Delta E_{i}}-\text { pre } \times \sqrt{\frac{(1+\varepsilon) \times \mu_{n} \times g}{\mu_{n} \times g+\varepsilon \times 930 \times \frac{P G V}{250}}} \\
\Delta y_{i}-\text { pre }=\frac{V_{\Delta E h r_{i}}-p r e^{2}}{2 \times \mu_{n} \times g}
\end{gathered}
$$

where $\zeta=1.5$ and $\varepsilon=0.25$.

The accuracies are shown in Figures 26 and 27: 


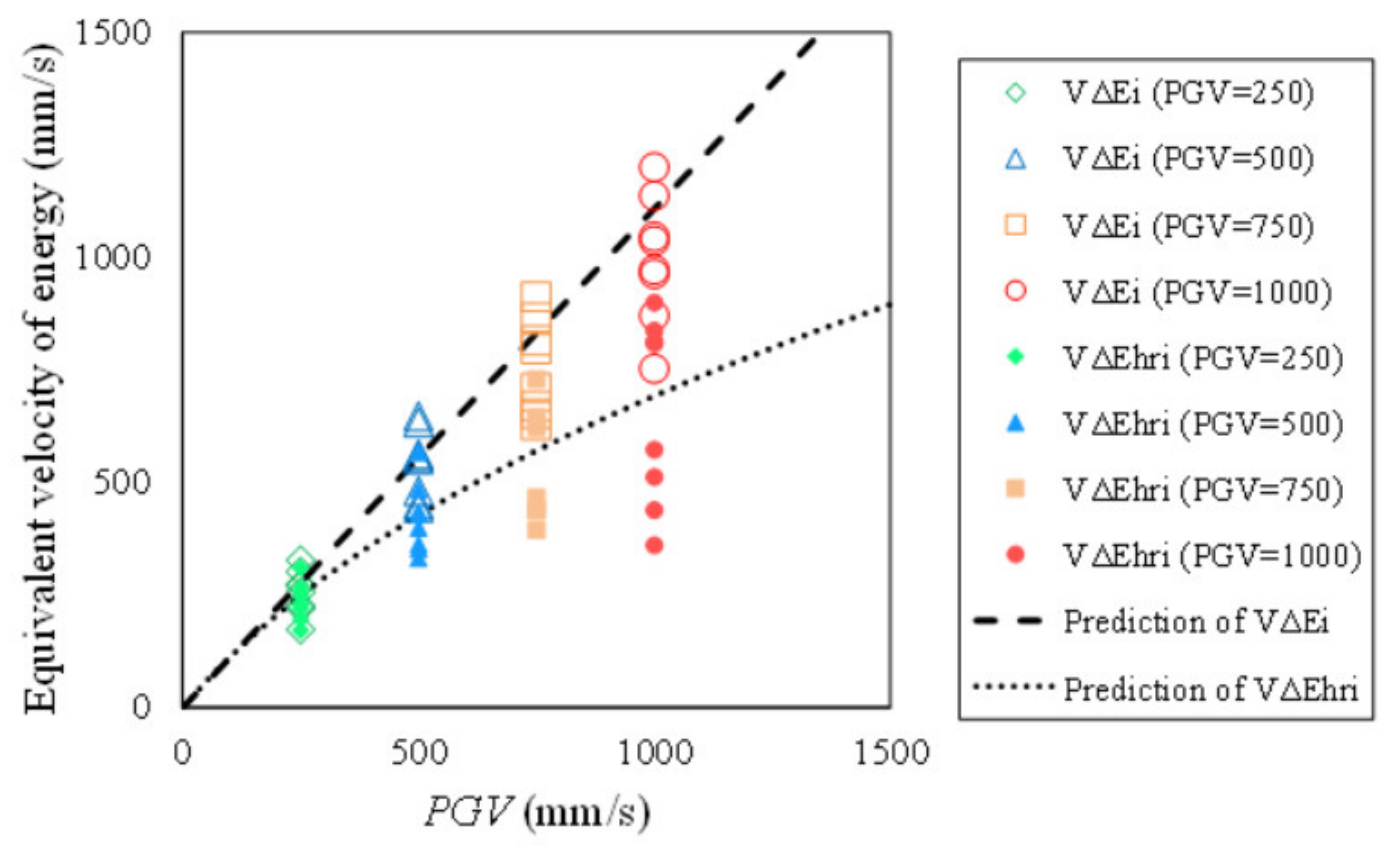

Figure 26. Prediction of $V_{\Delta E i}$ and $V_{\Delta E h r i}$ by only using PGV.

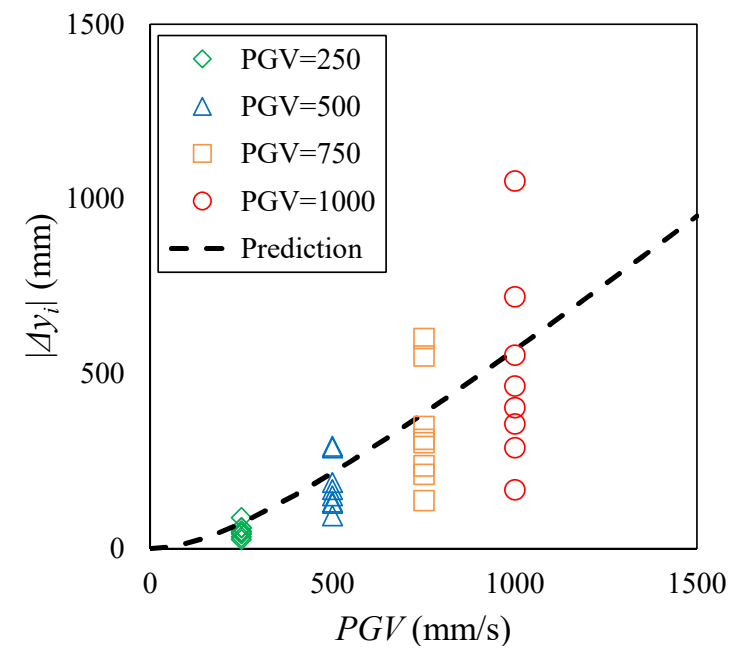

Figure 27. Prediction of $\left|\Delta y_{i}\right|$ by only using PGV.

In Figures 26 and 27, the data points show the analysis results for the maximum $V_{\Delta E i}, V_{\Delta E h r i}$ and $\Delta y_{i}$ under various earthquake inputs with their PGVs amplified to 250, 500, 750 and $1000 \mathrm{~mm} / \mathrm{s}$; the dashed line shows the prediction result under earthquake groups with different PGVs. The prediction results are a little above the average because of the selected value of the generalization parameter $\zeta$ and $\varepsilon$.

It should be mentioned that the prediction results would be made more conservative by enlarging the generalization parameter $\zeta$ in Equation (31) and by decreasing the generalization parameter $\varepsilon$ in Equation (32). By doing this, the maximum response displacement (the maximum $\Delta y_{i}$ can be considered as the conservative value of $y_{\max }$, as shown in Figures 11 and 27) and the maximum input energy of the isolation layer under all the earthquake inputs with same intensity could also be roughly predicted.

\section{Conclusions}

Full-scale dynamic tests were conducted under various conditions (the difference in surface pressure depending on the scale of the superstructure, relative speed between the upper and lower 
concave plate, amplitude, etc.) to evaluate the effects of surface pressure, velocity and temperature rise due to friction heat on the dynamic behavior of DCFP bearings for seismic isolation structures.

The combination of these effects with two temperature simulation models and two friction models (the precise model and the simplified model) was proposed. After verifying the friction models by full-scale dynamic tests, it was found that the simplified model could simulate the DCFP bearing to the same standard as the precise model with much less calculation time. Furthermore, after comparing the two models by response analysis, the simplified model was further proved to be able to replace the precise model.

Even though temperature and velocity have large influences on the value of the friction coefficient, the friction coefficient can be taken as constant, regardless of them, with sufficient accuracy in estimating the response force of the isolation layer under certain response displacements and in predicting the response displacement of the isolation layer (relative displacement between the upper structure and ground) under earthquakes. Furthermore, in this study, the constant friction coefficient was defined as the nominal friction coefficient, $\mu_{n}$.

By observing the response analysis results, it was found that large ground velocity pulses will lead to large input energies and large response displacements of the isolation layer, simultaneously. Then, by theoretical derivation, it was found that the response displacement and the energy transfer could be predicted directly from ground velocity using a constant friction coefficient.

After verifying and optimizing the prediction method by analyzing the data, a simplified prediction method for energy transfer and response displacement was proposed. Using this method, the energy transfer and response displacement could be predicted for DCFP bearings and any friction coefficient during any earthquake with sufficient accuracy.

In order to generalize the prediction method so that it could be easily used in design, specific earthquake characteristics in the method were replaced by general characteristics that could be used to describe a group of earthquakes in a construction site, such as PGV. Additionally, the generalized method can provide conservative predictions, and the conservativeness degree can be adjusted by adjusting the generalization parameters, $\zeta$ and $\varepsilon$.

After these fundamental studies on the relationship between the response and the input energy of the DCFP bearing and the input earthquake records under unidirectional excitation, this relationship under bidirectional earthquake excitation will also be studied, with the aim of proposing a more direct and simple method for predicting the response of the isolation layer from ground motions and providing more perspectives in relation to the existing design codes.

Author Contributions: Conceptualization, S.Y. (Shinsuke Yamazaki), A.W. and M.T.; Methodology, S.K. and S.Y. (Satoshi Yamada); Software, J.L.; Validation, J.L.; Formal Analysis, J.L.; Investigation, S.Y. (Shinsuke Yamazaki), A.W. and M.T.; Resources, S.Y. (Shinsuke Yamazaki), S.K. and S.Y. (Satoshi Yamada); Data Curation, J.L.; Writing-Original Draft Preparation, J.L.; Writing—Review \& Editing, S.K., S.Y. (Satoshi Yamada), S.Y. (Shinsuke Yamazaki), A.W. and M.T.; Visualization, J.L.; Supervision, S.K., S.Y. (Satoshi Yamada) and S.Y. (Shinsuke Yamazaki); Project Administration, S.K., S.Y. (Satoshi Yamada) and S.Y. (Shinsuke Yamazaki); Funding Acquisition, S.K., S.Y. (Satoshi Yamada) and S.Y. (Shinsuke Yamazaki). All authors have read and agreed to the published version of the manuscript.

Funding: This research received no external funding.

Acknowledgments: The assistance of Cameron J. Black, Ian D. Aiken and Gianmario Benzoni during the experiment at the University of California, San Diego, is highly appreciated.

Conflicts of Interest: The authors declare no conflicts of interest.

\section{References}

1. Quaglini, V.; Dubini, P.; Poggi, C. Experimental assessment of sliding materials for seismic isolation systems. Bull. Earthq. Eng. 2012, 10, 717-740. [CrossRef] 
2. Lomiento, G.; Bonessio, N.; Benzoni, G. Friction Model for Sliding Bearings under Seismic Excitation. J. Earthq. Eng. 2013, 17, 1162-1191. [CrossRef]

3. Quaglini, V.; Bocciarelli, M.; Gandelli, E.; Dubini, P. Numerical Assessment of Frictional Heating in Sliding Bearings for Seismic Isolation. J. Earthq. Eng. 2014, 18, 1198-1216. [CrossRef]

4. Kumar, M.; Whittaker, A.S.; Constantinou, M.C. Characterizing friction in sliding isolation bearings. Earthquake Engng Struct. Dyn. 2015, 44, 1409-1425. [CrossRef]

5. Bianco, V.; Bernarddini, D.; Mollaioli, F.; Monti, G. Modeling of the temperature rises in multiple friction pendulum bearings by means of thermomechanical rheological elements. Arch. Civ. Mech. Eng. 2018, 19, 171-185. [CrossRef]

6. Minimum Design Loads and Associated Criteria for Buildings and Other Structures; ASCE/SEI 7-16; American Society of Civil Engineers (ASCE): Reston, VA, USA, 2016.

7. General rules, Eurocode 8. Design Provisions for Earthquake Resistance of Structures; Part 1: Seismic actions and rules for buildings. BS EN 1998-1; European Committee for Standardization: Brussels, Belgium, 2004.

8. Design Recommendations for Seismically Isolated Buildings; Architectural Institute of Japan: Tokyo, Japan, 2016; ISBN 978-4-8189-5000-9.

9. Akiyama, H. Earthquake-Resistant Limit-State Design for Buildings; University of Tokyo Press: Tokyo, Japan, 1985.

10. Iwan, W.D. Estimating Inelastic Response Spectra from Elastic Spectra. Earthq. Eng. Struct. Dyn. 1980, 8, 375-388. [CrossRef]

11. Uang, C.M.; Bertero, V.V. Use of Energy as a Design Criterion in Earthquake Resistant Design; Technical report, UCB/EERC88/18; University of California: Berkeley, CA, USA, 1988.

12. Hadjian, A.H. A Re-evaluation of Equivalent Linear Models for Simple Yielding Systems. Earthq. Eng. Struct. Dyn. 1982, 10, 759-767. [CrossRef]

13. Benzoni, G.; Seible, F. Design of the Caltrans Seismic Response Modification Device (SRMD) test facility (IWGFR-96). International Atomic Energy Agency (IAEA); International Working Group on Fast Reactors: Vienna, Austria, 1998; 325p, pp. 101-115.

14. Nishimoto, K.; Nakamura, H.; Hasegawa, H.; Wakita, N. Bearing Stress and Velocity Dependency of Spherical Sliding Bearing through Full-scale tests, Paper No. 21223. In Proceedings of the Summaries of Technical Papers of Annual Meeting, Fukuoka, Japan, 24-26 August 2016. (In Japanese)

15. Nakamura, H.; Nishimoto, K.; Hasegawa, H.; Nakamura, H. Predictive Method of a Temperature Rise and the Friction Coefficient of Spherical Sliding Bearing (Part 3), Paper No. 21232. In Proceedings of the Summaries of Technical Papers of Annual Meeting, Kanto, Japan, 4-6 September 2015. (In Japanese)

16. Yamazaki, S.; Nishimoto, K.; Watanabe, A. Experimental and Analytical Study of Spherical Sliding Bearing for Long Period Ground Motion, Paper No. 21059. In Proceedings of the Summaries of Technical Papers of Annual Meeting, Hokuriku, Japan, 3-6 September 2019. (In Japanese)

17. Constantinou, M.C.; Whittaker, A.S.; Kalpakidis, Y.; Fenz, D.M.; Warn, G.P. Performance of Seismic Isolation Hardware under Service and Seismic Loading; Report No. MCEER-07-0012; Multidisciplinary Center for Earthquake Engineering Research: Buffalo, NY, USA, 2007.

18. Japan Society of Mechanical Engineers (JSME). Heat Transfer, 5th ed.; JSME Data Books: Tokyo, Japan, 2009; pp. 284-285.

19. Li, J.; Kishiki, S.; Yamada, S.; Yamazaki, S.; Watanabe, A.; Nishimoto, K.; Nishimoto, K. Comparative Study of Numerical Models for Double Concave Friction Pendulum Bearing, Paper No. 21058. In Proceedings of the Summaries of Technical Papers of Annual Meeting, Hokuriku, Japan, 3-6 September 2019.

20. Takanori, I.; Masashi, N.; Shoichi, K.; Satoshi, Y.; Koji, N.; Atsushi, W. Experimental and Analytical Study on Spherical Sliding Bearing Subjected to Bidirectional Excitation (Part 1 Bidirectional loading tests and verification of mechanical model), Paper No. 21491. In Proceedings of the Summaries of Technical Papers of Annual Meeting, Tohoku, Japan, 4-6 September 2018; Volume 24, pp. 981-982. 
21. Kikuchi, M.; Ishii, K.; Yamamoto, M.; Higashino, M.; Kamoshita, N.; Nakamura, T.; Kouchiyama, O. Experimental study on horizontal Bi-axial mechanical properties of sliding supports with rubber-pad (Part 3: Simulation Analysis), Paper No. 21160. In Proceedings of the Summaries of Technical Papers of Annual Meeting, Nagoya, Japan, 12-14 September 2012. (In Japanese)

22. Kamoshita, N.; Yamamoto, M.; Minewaki, S.; Kikuchi, M.; Ishii, K.; Kouchiyama, O.; Nakamura, T. Horizontal bidirectional characteristics of elastic sliding bearings under various fluctuant vertical condition. AIJ J. Struct. Constr. Eng. 2014, 79, 453-461. (In Japanese) [CrossRef]

(C) 2020 by the authors. Licensee MDPI, Basel, Switzerland. This article is an open access article distributed under the terms and conditions of the Creative Commons Attribution (CC BY) license (http://creativecommons.org/licenses/by/4.0/). 